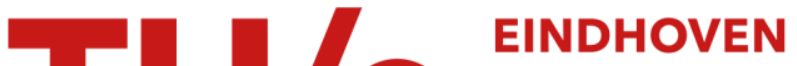

\section{Computational modeling of Diesel spray combustion with multiple injections}

Citation for published version (APA):

Zhou, Q., Lucchini, T., D'Errico, G., Maes, N. C. J., Somers, L. M. T., \& Lu, X. (2020). Computational modeling of Diesel spray combustion with multiple injections. SAE Technical Papers, 2020, [2020-01-1155].

https://doi.org/10.4271/2020-01-1155

DOI:

10.4271/2020-01-1155

Document status and date:

Published: $14 / 04 / 2020$

Document Version:

Accepted manuscript including changes made at the peer-review stage

Please check the document version of this publication:

- A submitted manuscript is the version of the article upon submission and before peer-review. There can be important differences between the submitted version and the official published version of record. People interested in the research are advised to contact the author for the final version of the publication, or visit the $\mathrm{DOI}$ to the publisher's website.

- The final author version and the galley proof are versions of the publication after peer review.

- The final published version features the final layout of the paper including the volume, issue and page numbers.

Link to publication

\section{General rights}

Copyright and moral rights for the publications made accessible in the public portal are retained by the authors and/or other copyright owners and it is a condition of accessing publications that users recognise and abide by the legal requirements associated with these rights.

- Users may download and print one copy of any publication from the public portal for the purpose of private study or research.

- You may not further distribute the material or use it for any profit-making activity or commercial gain

- You may freely distribute the URL identifying the publication in the public portal.

If the publication is distributed under the terms of Article 25fa of the Dutch Copyright Act, indicated by the "Taverne" license above, please follow below link for the End User Agreement:

www.tue.nl/taverne

Take down policy

If you believe that this document breaches copyright please contact us at:

openaccess@tue.nl

providing details and we will investigate your claim. 


\title{
Computational modeling of Diesel spray combustion with multiple injections
}

\author{
Author, co-author (Do NOT enter this information. It will be pulled from participant tab in \\ MyTechZone) \\ Affiliation (Do NOT enter this information. It will be pulled from participant tab in MyTechZone)
}

\begin{abstract}
Multiple injection strategies are commonly used in conventional Diesel engines due to the flexibility for optimizing heat-release timing with a consequent improvement in fuel economy and engineout emissions. This is also desirable in low-temperature combustion (LTC) engines since it offers the potential to reduce unburned hydrocarbon and $\mathrm{CO}$ emissions. To better utilize these benefits and find optimal calibrations of split injection strategies, it is imperative that the fundamental processes of multiple injection combustion are understood and computational fluid dynamics models accurately describe the flow dynamics and combustion characteristics between different injection events. To this end, this work is dedicated to the identification of suitable methodologies to predict the multiple injection combustion process. Two different approaches: Representative Interactive Flamelet model (RIF) and Tabulated Flamelet Progress Variable (TFPV) are compared and multiple ndodecane Spray A injections from the Engine Combustion Network are simulated using the RANS methods with both standard $k-\varepsilon$ and $k-\omega$ SST models. Evaluations of different turbulence and combustion models are carried out by comparing computed and measured data in terms of the mixing, penetration, first- and secondstage ignition characteristics, flame structures and soot formation.
\end{abstract}

\section{Introduction}

More and more compression ignition engines have been using a multiple injection strategy to work around the problems of contemporary improvement in power output, engine noise and emissions due to the increasing capabilities of modern injection equipment. This offers the flexibility to regulate injection strategy irrespective of engine speed and load and allows to deliver the fuel in multiple pulses per cycle [1]. The efficacies of such advanced injection strategy have been reported in previous studies: with optimized injection schemes, pilot injections in conventional Diesel engines have been proven to be capable of reducing fuel consumption, $\mathrm{NO}_{x}, \mathrm{CO}$ and unburned hydrocarbon (UHC) emissions at the sacrifice of deteriorated particular matter (PM) emissions due to the inhibited fuel-air mixing $[2,3]$. But this deficiency can be tackled by supplementary injections after the main delivery, known as post-injections providing oxidation of exhaust gas $[4,5]$, which may also significantly reduce engine-out UHC and $\mathrm{CO}$ emissions in low-temperature combustion (LTC) engines $[6,7]$.

To maximize the benefits of multiple injections and make it widely practical in automotive industries, it is imperative to understand the interaction between the mixture fields of two consecutive injections, the coupling between various ignition and combustion stages as well as the emission characteristics. However, those involved physical phenomena are very complex and its mechanisms are not well known, preventing an efficient and complete optimization of engine performance. Such aspect has motivated researchers to look towards computational fluid dynamics (CFD) simulations for guidance, which represents a useful tool to provide critical insights into the highly transient phenomena that are difficult to fully quantify by experiments [8-11]. The success of accurately capturing multiple injection combustion strongly depends on the quality and reliability of the underlying models describing spray development, fuel-air mixing and subsequent ignition and flame characteristics, which has attracted increasing interest from many researchers to develop and evaluate the CFD methodologies in mimicking involved physics [1214].

Turbulence modeling is still one of the most, if not the most, critical issues when approaching engineering CFD simulations of practical interest. Despite the fact that the standard $k-\varepsilon$ model has been and is still widely used in combustion vessel and Diesel engine simulations [15-17], the recognition that it cannot provide satisfactory prediction of streamline curvature and flow separation in the near wall region, which has significant effects in IC engines due to the combination of high Reynolds number and complex geometries, has pushed researchers towards more reliable turbulence models $[16,18,19]$. A possible alternative is the $k-\omega$ SST (Shear Stress Transport) model proposed in $[20,21]$ using the original $k-\omega$ in the near wall region and gradually switching to standard $k-\varepsilon$ model in the wake region and free shear layers, which also introduces a modification to eddy viscosity to account for the transport of the principle turbulent shear stress, having the potential to better describe the entrainment and mixing rates after the flame-wall contact [22]. Prior to applying $k-\omega$ SST model to practical Diesel engine simulation, it is of crucial importance to see how it performs in capturing high-pressure spray characteristics. For this reason, this work is carried out to assess and compare the capabilities of standard $k-\varepsilon$ and $k-\omega$ SST models in simulating Spray A with double injections under both non-reacting and reacting conditions as a primary attempt to enable confident application of $k-\omega$ SST model in practical engine settings.

Added to the existing challenging modeling of auto-igniting highpressure fuel sprays, the turbulent flow field evolution of multiple injection events, as well as the complex chemical-thermal interaction between the first and second pulses matters considerably and has to be properly taken into account [23]. To this end, lots of efforts have been dedicated to improve, develop and validate the combustion models including transport probability density function (TPDF) [24,

Page 1 of 17

$10 / 30 / 2019$ 
25], conditional moment closure (CMC) [23, 26, 27] and representative interactive flamelet (RIF) [28-30] to simulate the turbulent spray flames with split injections. For what concerns RIF model approximating the flame structure as a set of laminar diffusion flames, a single flamelet formulation is generally used to reduce the computational time but this aspect limits its capability to reproduce the flame stabilization process being closely linked with the soot formation, which is one of the most critical issues in the case of multiple injections [31-33]. A possible alternative to overcome this limitation and achieve accurate, fast and robust results can be represented by tabulated kinetics, where reaction rates and chemical compositions are calculated on the basis of assumed flame structures, stored in an existing look-up table as function of state variables being temperature, pressure, mixture fraction and a combustion variable [34]. With such quantities and a presumed probability density function, local composition or reaction rate can be computed. Such approaches have been successfully applied to simulate practical flame configurations in the past years [35-37]. Among them, one interesting approach is called tabulated flamelet progress variable (TFPV), which is grounded on the tabulation of laminar diffusion flamelets for different scalar dissipation rate levels, performing in a similar way as the so-called approximated diffusion flame [37-39]. Following the successful application of the TFPV approach in 3D simulations including spray flames of Engine Combustion Network's (ECN) Spray A, light- and heavy-duty Diesel engines employing single injection [40,41], the present study seeks to assess its predictive capability of modeling multiple injection combustion. TFPV is expected to provide a more realistic description of the physical processes than RIF, which is the current start-of-the-art combustion model in Diesel engine simulations, since it takes into account the local flow conditions and transport of the progress variable. It should be highlighted that for both models, the mixture fraction is assumed to evolve from 0 to 1 in this work.

The proposed approaches were implemented in the Lib-ICE code, which is on the basis of OpenFOAM ${ }^{\circledR}$ technology [42] and includes a set of libraries and solvers for internal combustion engine simulations [43-45]. Non-reacting sprays with single and double injections were first simulated to validate the accuracy of chosen spray models and to compare $k-\varepsilon$ and $k-\omega$ SST models in terms of predicting spray penetrations and mixture fraction distributions. Validation and comparison of RIF and TFPV combustion models were then carried out by simulating n-dodecane Spray A with a split injection setup $(0.5 \mathrm{~ms} / 0.5-\mathrm{ms}$ dwell $/ 0.5 \mathrm{~ms})$ under different ambient conditions presented in [46, 47], where vapor penetration and progression of first- and second-stage ignitions were measured by high speed imaging techniques and temporal and spatial distributions of formaldehyde $\left(\mathrm{CH}_{2} \mathrm{O}\right)$ were identified by simultaneous single-shot planar laser-induced fluorescence (PLIF) imaging [48]. In the last part of this study, the $k-\omega$ SST model was applied to both TFPV and RIF cases in an attempt to further evaluate its capability in modeling transient high-pressure spray flames.

\section{Combustion models}

\section{Representative Interactive Flamelet (RIF)}

This model is based on the laminar flamelet concept, assuming that the smallest turbulence time and length scales are much larger than chemical ones and that a locally undisturbed sheet exits where reactions occur [49]. In this way, the temporal evolution of all reacting scalars only depends on the mixture fraction $\mathrm{Z}$, which is related to the local fuel-to-air ratio for non-premixed combustion.
Hence, local chemical compositions can be estimated from the $\mathrm{Z}$ field in the CFD domain with its sub-grid distribution represented by a $\beta$ pdf. Therefore, transport equations for mixture fraction $\mathrm{Z}$ and its variance need to be solved:

$\frac{\partial \bar{\rho} \tilde{Z}}{\partial t}+\nabla(\bar{\rho} \widetilde{U} \tilde{Z})-\nabla\left(\widetilde{\mu_{t}} \nabla \tilde{Z}\right)=\dot{S}_{Z}$

$\frac{\partial \bar{\rho} \widetilde{Z^{\prime \prime 2}}}{\partial t}+\nabla\left(\bar{\rho} \widetilde{U} \widetilde{Z^{\prime \prime 2}}\right)-\nabla\left(\widetilde{\mu_{t}} \nabla \widetilde{Z^{\prime \prime 2}}\right)=2 \frac{\widetilde{\mu_{t}}}{S c}|\nabla \tilde{Z}|^{2}-\bar{\rho} \tilde{\chi}$

where $\dot{S}_{Z}$ is the liquid mass evaporation rate per unit volume and the sink term in Eq. 2 represents the average scalar dissipation rate being a function of turbulent time scale and mixture fraction variance:

$\tilde{\chi}=C_{\chi} \frac{\tilde{\varepsilon}}{\tilde{k}} \widetilde{Z^{\prime \prime 2}}$

where $C_{\chi}$ was set to 2 in this work. To properly account for local

flow and turbulence effects on flame structure and to predict flame stabilization, multiple flamelets can be used. Each one represents a certain portion of the injected fuel mass and the chemical composition in each cell is then computed from the mixture fraction and flamelet marker distribution as follows:

$\widetilde{Y}_{\imath}(\vec{x})=\sum_{j=1}^{N_{f}} M_{j} \int_{0}^{1} Y_{j, i}(\tilde{Z}) P\left(\tilde{Z}, \widetilde{Z^{\prime \prime 2}}\right) d Z$

For each flamelet marker, the following transport equation is solved:

$\frac{\partial \bar{\rho} \widetilde{M_{J}}}{\partial t}+\nabla\left(\bar{\rho} \widetilde{U} \widetilde{M_{J}}\right)-\nabla\left(\frac{\widetilde{\mu_{t}}}{S c_{t}} \nabla \widetilde{M}_{J}\right)=\dot{S}_{M_{j}}$

where the source term $\dot{S}_{M_{j}}$ corresponds to $\dot{S}_{Z}$ only for a specified interval of the injection duration, while it is zero elsewhere. Flamelet markers must also satisfy the following relation:

$Z=\sum_{j=1}^{N_{f}} M_{j}$

The local flame structure is defined by the flamelet equations, which are solved assuming unity Lewis number in the mixture fraction space:

$\rho \frac{\partial Y_{i}}{\partial t}=\rho \frac{\chi_{Z}}{2} \frac{\partial^{2} Y_{i}}{\partial Z^{2}}+\dot{\omega}_{i}$

$\rho \frac{\partial h_{s}}{\partial t}=\rho \frac{\chi_{Z}}{2} \frac{\partial^{2} h_{s}}{\partial Z^{2}}+\dot{q}_{s}$

where $Y_{i}$ is the mass fraction of species $I, \rho$ is the density, $\mathrm{Z}$ is the mixture fraction, $\dot{\omega}_{i}$ is the chemical source term of species $i, h_{s}$ is the specific sensible enthalpy, and $\dot{q}_{s}$ is the heat release due to chemical reactions. Eqs. 7-8 are solved on a 1-D mesh with the finite volume method, by using a stiff ordinary differential equation solver to properly compute $\dot{\omega}_{i}$. The effects of mixing related to turbulence and

Page 2 of 17 
flow field are grouped into the scalar dissipation rate term $\chi_{Z}$ expressed as:

$\chi_{Z}=\widehat{\chi_{s t}, J} \frac{f(Z)}{f\left(Z_{s t}\right)}$

In Eq. 9, $f(Z)$ has an erfc-profile [50], while the scalar dissipation rate at stoichiometric mixture fraction conditions $\widehat{\chi_{s t},}$ for each flamelet is computed as an average of the local values in each CFD cell. It accounts for the flamelet maker distribution $M_{j}$ according to:

$\widehat{\chi_{s t, j}}=\frac{\int_{V} M_{j} \chi_{s t, l}^{3 / 2} \rho P\left(Z_{s t}\right) d V^{\prime}}{\int_{V} M_{j} \chi_{s t, l}^{1 / 2} \rho P\left(Z_{s t}\right) d V^{\prime}}$

where $P$ is the $\beta$-pdf function, whose parameters depend on the mixture fraction and its variance. In each cell, the local stoichiometric scalar dissipation rate is computed based on the Hellstrom formulation:

$\chi_{s t, l}=\frac{\chi}{\int_{0}^{1} \frac{f(Z)}{f\left(Z_{s t}\right)} \tilde{P}(Z) d Z}$

The operation of RIF combustion models is summarized in Fig. 1, illustrating the mutual interactions between the CFD and flamelets domain. At each time-step, average stoichiometric scalar dissipation rate values are passed to each flamelet, which solves Eqs. 7-8 accordingly. The chemical composition in the CFD domain is computed from the mixture fraction, its variance and the flamelet marker distribution. Temperature is updated from new chemical composition and total enthalpy, whose variation is only due to flow and spray evaporation. More details about its implementation in LibICE can be found in [51, 52].

As computation time is a function of the number of flamelets chosen for the physical domain, it goes up very fast as the number of flamelets is increased [53]. For this reason, a single flamelet formulation is used for each injection event in the present work to reduce the computation cost.

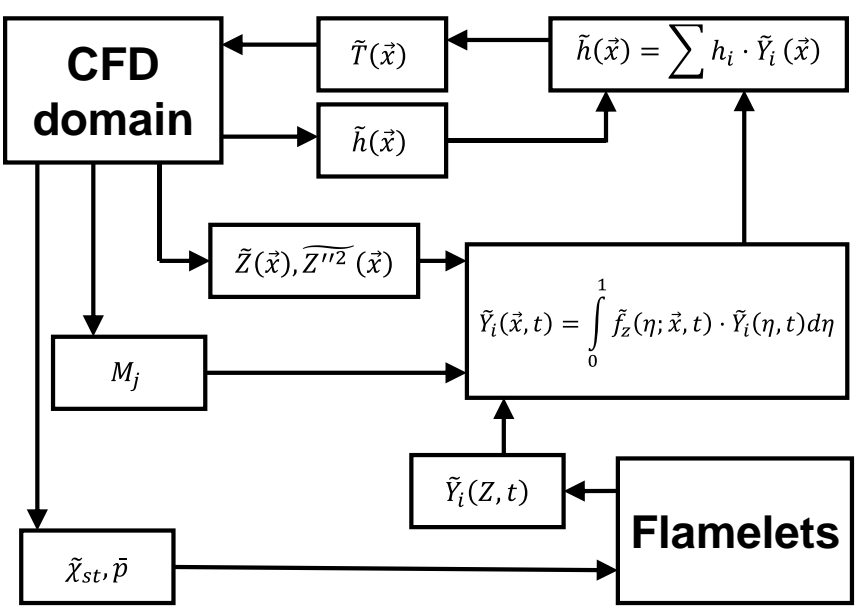

Figure 1. Operation of representative interactive flamelet model (RIF).

\section{Tabulated Flamelet Progress Variable (TFPV)}

To clearly explain the TFPV combustion model, the generation of chemistry table and operation principle of tabulated kinetics are first introduced.

Fig. 2 illustrates how chemistry is tabulated in the proposed approach. A chemical mechanism needs to be specified, as well as a range of initial conditions for homogeneous constant pressure reactor calculations in terms of:

- $\quad$ Mixture fraction $Z$;

- Ambient pressure $p$;

- Initial reactor temperature $T u$;

- Residual gas fraction $E G R$

Based on these quantities, chemical composition is initialized, and $T u$ is calculated based on the values of expected oxidizer temperatures $\left(T_{Z=0}\right)$, fuel temperature $\left(T_{Z=1}\right)$ and its heat of evaporation $\left(h_{l}\right)$ :

$h(Z)=(1-Z) \cdot h\left(T_{Z=0}\right)+Z \cdot h\left(T_{Z=1}\right)-Z \cdot h_{l}\left(T_{Z=1}\right)$

$T_{u}(Z)=T(h(Z))$

The constant pressure, auto-ignition calculations are performed under specified conditions by solving chemical species equations:

$\frac{\mathrm{d} Y_{i}}{\mathrm{dt}}=\dot{\omega}_{l}\left(T, p, Y_{i}, \cdots, Y_{n}\right)$

with reactor temperature $T$ computed directly from the initial enthalpy value. After every time step, evaluation of progress variable $C$ together with computation of chemical compositions by means of the virtual species approach are performed. The definition of combustion progress variable proposed by Lehtiniemi et al. [37] was adopted in this work, known as $h_{298}$, where $C$ equals the heat release due to combustion. $C$ is calculated as the difference between the current and initial value of the reactor formation enthalpy:

$C=\sum_{i=1}^{N S} h_{298, i} \cdot Y_{i}(t)-\sum_{i=1}^{N S} h_{298, i} \cdot Y_{i}(0)$

where $N s$ is the total number of chemical species used by the specified mechanism. At the end of each reactor calculation, progress variable reaction rates, chemical compositions, minimum and maximum progress variable values $\left(C_{\min }\right.$ and $\left.C_{\max }\right)$ are stored as function of the discrete values of the normalized progress variable $c$ :

$c=\frac{C-C_{\min }}{C_{\max }-C_{\min }}$

The progress variable reaction rate is computed with the forward differencing scheme as following:

$\dot{c}_{i}=\frac{c_{i+1}-c_{i}}{t_{i+1}-t_{i}}$

Page 3 of 17

$10 / 31 / 2019$ 
To avoid excessive memory consumption, only seven virtual species are tabulated instead of the entire set of species. Their mass fractions are computed in order to preserve the main thermo-chemical properties of the full set used in chemistry mechanism [54]. The table also includes the mass fraction of chemical species which are of interest to the user ( $Y_{o}$ in Fig. 2), either for post-processing reason or because they are relevant for the formation of the main pollutants and have to be used by the related sub-models.

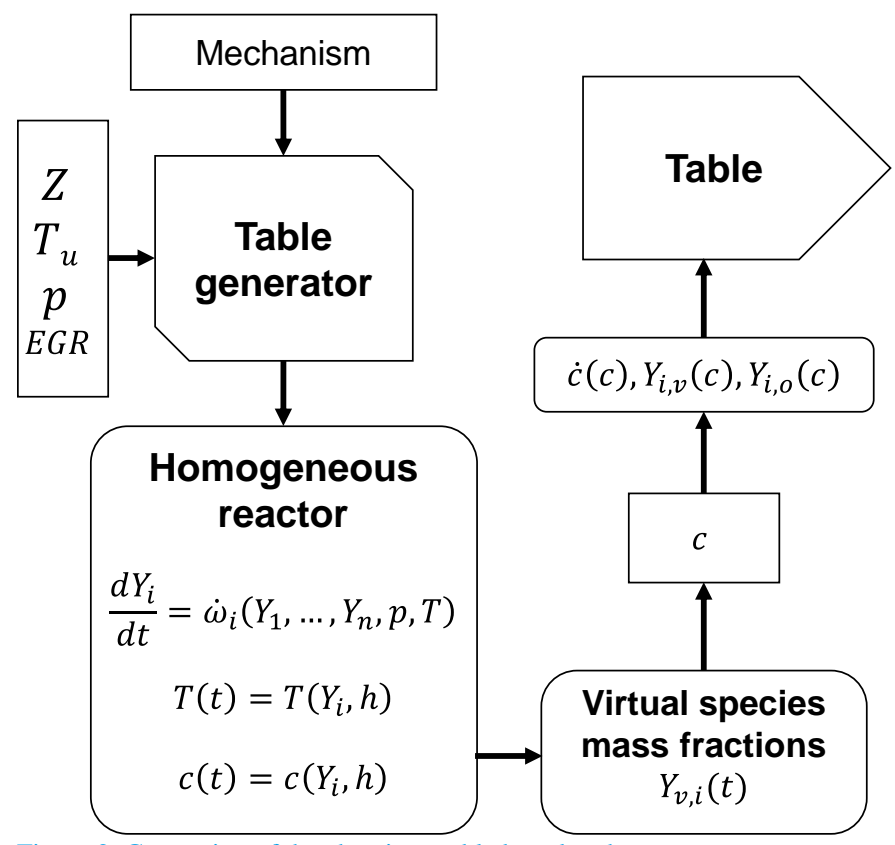

Figure 2. Generation of the chemistry table based on homogeneous reactor assumption

The applications of this homogenous chemistry table have been discussed in detail in $[54,55]$. A summary of application methods is given as follows:

- Directly, providing reaction rates and chemical composition to the CFD solver, with so-called "tabulated well-mixed" (TWM) approach;

- Embedded into RIF model, where flamelet equations are solved only for progress variable and energy, allowing a significant reduction of the computational time (tabulated RIF (TRIF) approach);

- By generating lookup tables based on more complex structures and introducing additional parameters such as the mixture fraction variance or scalar dissipation rate.

Fig. 3 presents the operation principle of combustion models based on tabulated kinetics. Besides the transport equations for mixture fraction $Z$, its variance $\widetilde{Z^{\prime \prime 2}}$, it is also necessary to solve additional equations for progress variable $C$ and unburned gas enthalpy $h_{u}$ which is then used to estimate the unburned gas temperature $T_{u}$ :

$\frac{\partial \bar{\rho} \tilde{C}}{\partial t}+\nabla(\bar{\rho} \widetilde{U} \tilde{C})-\nabla\left(\frac{\widetilde{\mu_{t}}}{S c_{t}} \nabla \tilde{C}\right)=\bar{\rho} \dot{C}$

$\frac{\partial \bar{\rho} \widetilde{h_{u}}}{\partial t}+\nabla\left(\bar{\rho} \widetilde{U} \widetilde{h_{u}}\right)-\nabla\left(\widetilde{\alpha_{t}} \nabla \widetilde{h_{u}}\right)=\dot{Q}_{s}+\frac{\bar{\rho}}{\overline{\rho_{u}}} \cdot \frac{D \bar{p}}{D t}$ where $\widetilde{\alpha_{t}}$ is the turbulent thermal diffusivity and $\overline{\rho_{u}}$ is the density of unburned gases which is computed from cell pressure, chemical composition at $C=0$ and $T_{u} . \dot{Q}_{S}$ is the term related to spray evaporation. In case sub-grid mixing effects are considered, the stoichiometric scalar dissipation rate $\chi_{s t}$ is also computed. The lookup table is then accessed with local cell values of $\mathrm{Z}, \widetilde{Z^{\prime \prime 2}}, \mathrm{C}, \mathrm{p}, \mathrm{T}_{\mathrm{u}}$ and $\chi_{s t}$, and in turn it provides the chemical compositions and the progress variable reaction rate to the solver by means of an inverse, distance weighted technique interpolation. However, it must be pointed out that progress variable diffused from cool flame regions could ignite rich mixtures $(\phi>3)$ instantaneously, and high values of $C$ will be diffused back to lean or stoichiometric mixtures leading to a very anticipated auto-ignition. To avoid this, reaction rates are set to zero in regions where dual-stage ignition does not happen, corresponding approximately to $\phi=3$.

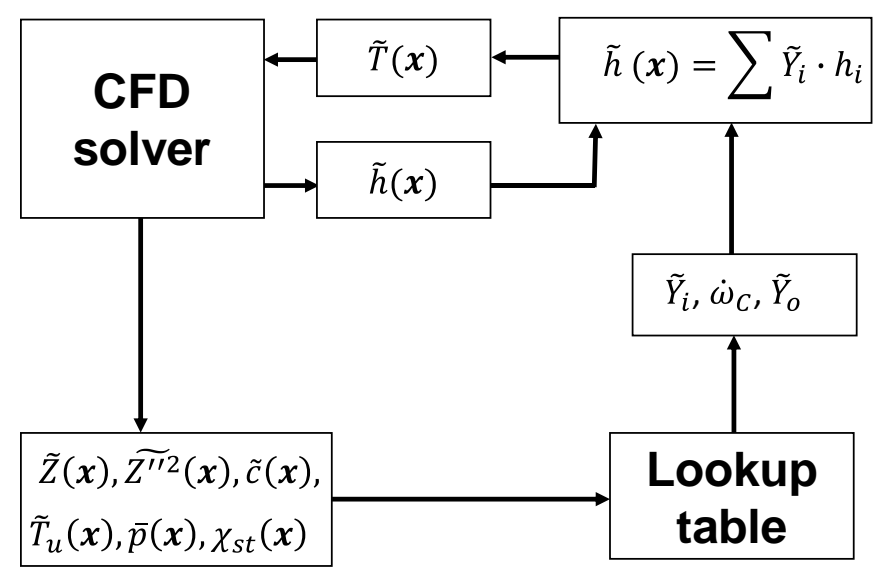

Figure 3. Operation of combustion models based on tabulated kinetics

The main purpose of the TFPV model is to provide a realistic description of the turbulent diffusion flame, considering turbulence/chemistry interaction, sub-grid mixing and premixed flame propagation. This requires solving a transport equation for progress variable in the CFD domain where the source term depends on local thermodynamic conditions $\left(p, T_{u}\right)$, mixture fraction $Z$, mixture fraction variance $\widetilde{Z^{\prime \prime 2}}$, and scalar dissipation rate $\chi_{s t}$, In this way, the TFPV model is expected to give correct predictions of:

- Extinction in the near-nozzle region where the scalar dissipation rate is very high;

- Re-ignition due to progress variable convection and diffusion;

- Flame stabilization process including effects of both premixed and diffusive flame propagation.

The TFPV library is based on unsteady diffusion flame calculations performed with the TRIF model, in a similar way as [37-39], with the so-called approximated diffusion flames approach. Generation of the TFPV library is shown in Fig. 4. A range of temperatures, pressures, and scalar dissipation values are specified by the user for which unsteady diffusion flame calculations are performed using the TRIF model. At any timestep, it is possible to estimate the chemical compositions in terms of the virtual species $Y_{i, v}(Z, t)$, and the progress variable $C(Z, t)$ for the prescribed values of $Z$. From userspecified mixture fraction segregation factor values:

$$
S_{Z}=\frac{\widetilde{Z^{\prime \prime 2}}}{Z(1-Z)}
$$

Page 4 of 17 
Mixture fraction variance $\widetilde{Z^{\prime \prime 2}}$ is computed and results of TRIF calculations are processed to account for its effects on progress variable and chemical composition as follows:

$$
\begin{aligned}
& Y_{i}\left(Z, \widetilde{Z^{\prime \prime 2}}\right)=\int_{0}^{1} Y_{T R I F}(Z) \beta\left(Z, \widetilde{Z^{\prime \prime 2}}\right) d Z \\
& C\left(Z, \widetilde{Z^{\prime \prime 2}}\right)=\int_{0}^{1} C_{T R I F}(Z) \beta\left(Z, \widetilde{Z^{\prime \prime 2}}\right) d Z
\end{aligned}
$$

At the end of any diffusion flame calculation, for all values of $Z$ and $\widetilde{Z^{\prime \prime 2}}$, the progress variable is normalized, and its reaction rate is estimated. Computed data are then interpolated for the specified progress variable values to generate the table.

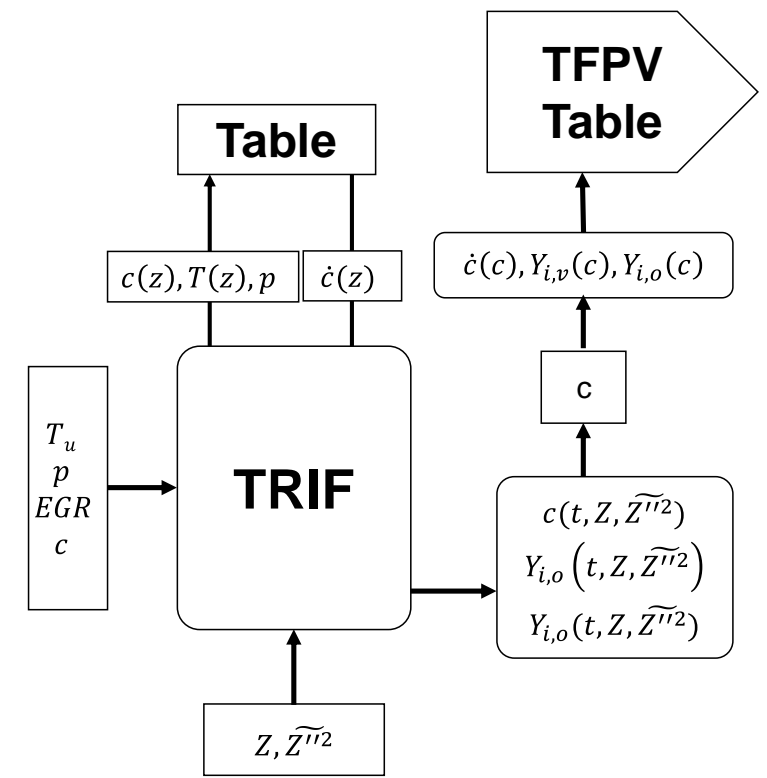

Figure 4. Generation of chemistry table used for tabulated flamelet progress variable model (TFPV).

\section{Soot model}

Soot emissions were estimated by means of the semi-empirical model proposed by Leung et al. [56]: two transport equations for soot particle number density $N_{p}$ and volume fraction $f_{v}$ are solved, with source terms related to nucleation, coagulation, surface growth and oxidation processes as follows:

$\dot{\omega}_{N_{p}}=\dot{\omega}_{i n c}-\dot{\omega}_{c o a g}$

$\dot{\omega}_{f_{v}}=\dot{\omega}_{\text {inc }}+\dot{\omega}_{g r o w}-\dot{\omega}_{o x i, O_{2}}-\dot{\omega}_{o x i, O H}$

Inception and surface growth source terms $\left(\dot{\omega}_{\text {inc }}\right.$ and $\left.\dot{\omega}_{\text {grow }}\right)$ depend linearly on acetylene $\left(\mathrm{C}_{2} \mathrm{H}_{2}\right)$ concentration as a soot precursor, calculated based on the following assumed reaction steps:

Inception:

$$
\mathrm{C}_{2} \mathrm{H}_{2} \rightarrow 2 \mathrm{C}(\mathrm{s})+\mathrm{H}_{2}
$$

Surface growth: $\quad \mathrm{C}_{2} \mathrm{H}_{2}+n C(s) \rightarrow(n+2) C(s)+\mathrm{H}_{2}$

To account for the reduced reactivity of soot particles over time, Leung et al. [56] assumed the soot surface growth rate proportional to the square root of the specific surface area, which is consistently employed in the present work. Coagulation of soot particles $\left(\dot{\omega}_{\text {coag }}\right)$ presented in the source term of the number density equation is modeled using the normal square dependence. Soot oxidation depends on $\mathrm{O}_{2}$ and $\mathrm{OH}$ concentrations, following [56]. It is well known that the formation of soot is a rather slow process compared to the other species involved in the combustion chemistry, thus the flamelet approach based on the fast chemistry assumption, solving $f_{v}$ and $N_{p}$ equations in the mixture fraction space might be questionable. For this reason, transport equations for the soot model are solved in the CFD domain and source terms are computed on the basis of the local species concentrations and thermodynamic conditions.

\section{Numerical framework}

Multi-dimensional CFD simulations were conducted using Lib-ICE, a set of solvers and libraries for comprehensive IC engine simulations developed under the OpenFOAM technology [43, 45]. The Reynoldsaveraged Navier-Stokes (RANS) formulation was used for describing the gas phase while turbulence was modeled using both standard $k-$ $\varepsilon$ and $k-\omega$ SST models with the so-called round jet correction in order to predict the penetration of fuel vapor jet [57]. For the standard $k-\varepsilon$ model, $C_{1}$ was increased to 1.50 in present work, which is a common practice in simulating spray and turbulent gas jet. For the standard $k-\omega$ SST model, $\gamma_{2}$ was initially chosen by the correspondence between $k-\varepsilon$ and $k-\omega$ model constants and later was recalibrated based on non-reacting spray A simulations, with a final value of 0.60. The combination of PISO and SIMPLE techniques, known as the PIMPLE algorithm, was employed to couple pressure and velocity equations, ensuring both stability and accuracy [58]. The evolution of liquid spray was computed using a Discrete Droplet Method (DDM), where the spray is assumed to be composed of a set of computational parcels, each one representing droplets with the same properties. Parcels evolve into the CFD domain in a Lagrangian fashion, exchanging mass, momentum and energy with the continuous gas phase. Specific sub-models are necessary to mimic fuel atomization, breakup, heat transfer, evaporation, collision and wall impingement. In the present work, a Rosin-Rammler probability density function (PDF) was used to generate droplet parcels, followed by activating the Reitz-Diwakar model $[59,60]$, which reduces second breakup to a continuous decrease in droplet radius. Droplet evaporation was computed from the droplet size and Spalding mass number while the Ranz-Marshall correlation was used to model heat transfer between liquid and the surrounding gas phase. Collision and coalescence were neglected since they have a minimum influence on evaporating spray simulations $[61,62]$.

All the simulations were performed considering the entire 3D domain of the cubic Sandia combustion vessel $(108 \times 108 \times 108 \mathrm{~mm})$ [63]. The cross-section view of computational domain for $k-\varepsilon$ model cases is shown in Fig. 5, where the injection direction is depicted with the red arrow. The mesh is refined near the injector and its resolution progressively decreases when moving downstream of the injector and the combustion vessel walls to save the computational time. The mesh is composed of approximately 0.4 million cells with optimal cell sizes of $0.2 \mathrm{~mm}$ in the vicinity of nozzle. Similar to $k-$ $\varepsilon$ mesh, the $k-\omega \mathrm{SST}$ mesh is more refined especially in the near nozzle region, having about 1 million cells and a minimum mesh size of $0.1 \mathrm{~mm}$. This resolution is adopted following a mesh sensitivity analysis conducted by the authors (but not presented here), which showed that the chosen resolution is a good compromise between computational efforts and prediction accuracy.

Page 5 of 17 


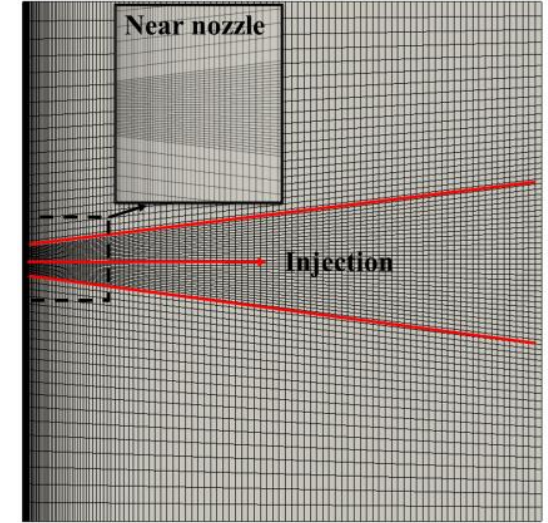

Figure 5. Cross-section of the computational domain for the $k-\varepsilon$ model.

\section{Results and discussions}

This study pursues the final objective to comprehensively assess the potential and limits of the CFD methodologies proposed for describing fuel-air mixing and combustion processes of turbulent high-pressure spray flames with split injections. To this end, the validation and evaluation procedure consisted in simulating both nonreacting and reacting high-pressure sprays, following these steps:

- $\quad$ Spray calibrations for $k-\varepsilon$ and $k-\omega$ SST models;

- Validation of $k-\varepsilon$ and $k-\omega$ SST models in non-reacting Spray A split injection simulations;

- Assessment of predictive capability of RIF and TFPV combustion models for split injections;

- $\quad$ Evaluation of $k-\varepsilon$ and $k-\omega$ SST models in reacting Spray A split injection simulations.

The experimental results used for the aforementioned procedures originate from the ECN database [63] (non-reacting Spray A with single injection) and previous work of split injections presented by Skeen et al. [33, 46] (non-reacting: $900 \mathrm{~K}, 22.8 \mathrm{~kg} / \mathrm{m}^{3}$; reacting: 750 $\mathrm{K}, 800 \mathrm{~K}$ and $900 \mathrm{~K}, 22.8 \mathrm{~kg} / \mathrm{m}^{3}$ ) and Maes et al. [47] (reacting: 900 $\mathrm{K}, 22.8 \mathrm{~kg} / \mathrm{m}^{3}$ ).

\section{Non-reacting conditions}

To validate the employed numerical setups (e.g. turbulence and spray sub-models, mesh size and distribution), four operating points are selected from the available ECN database of non-reacting single injection conditions, across the parametric variations of ambient density $\left(22.8 \mathrm{~kg} / \mathrm{m}^{3}, 15.2 \mathrm{~kg} / \mathrm{m}^{3}\right.$ and $\left.7.6 \mathrm{~kg} / \mathrm{m}^{3}\right)$ and temperature $(900$ $\mathrm{K}, 700 \mathrm{~K})$. Fig. 6 compares the measured and computed liquid and vapor penetrations at the Spray A baseline condition corresponding to an ambient density of $22.8 \mathrm{~kg} / \mathrm{m}^{3}$ and an ambient temperature of 900 $\mathrm{K}$, evidencing that rather good agreements are achieved by the $k-\varepsilon$ model while $k-\omega$ SST simulations overpredict the vapor penetration during the early stages (around $0.15 \mathrm{~ms}$ ASOI). Similar performance of these two models is also shown at other three conditions in Fig. 7. It is evident that such discrepancy of the $k-\omega$ SST model is due to the prediction of liquid penetration at the initial stage, where particles penetrate much faster into the gas phase from 0 to $0.1 \mathrm{~ms}$ depicted in Fig. 6. However, the achievement of such accuracy is adequate since the present work mainly focuses on simulations of turbulent spray flames taking place after the transient liquid penetration. It is worth mentioning that improving the results from the $k-\omega \mathrm{SST}$ model is possible if finer mesh and smaller time step are used, at the expense of a significant increase in computational cost.

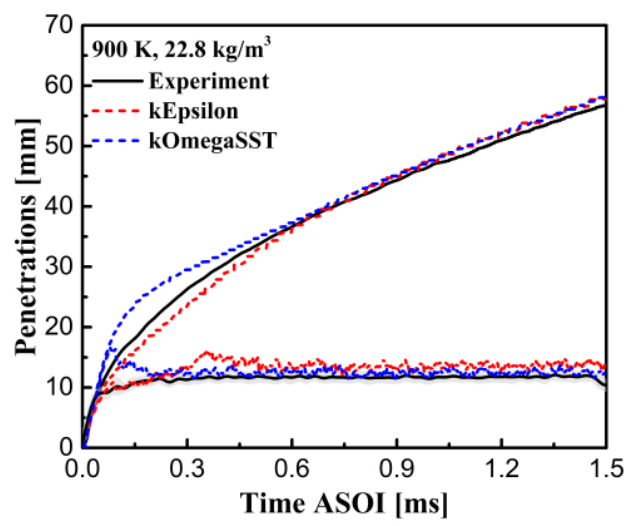

Figure 6. Measured and computed liquid and vapor penetration for nonreacting Spray A baseline case.

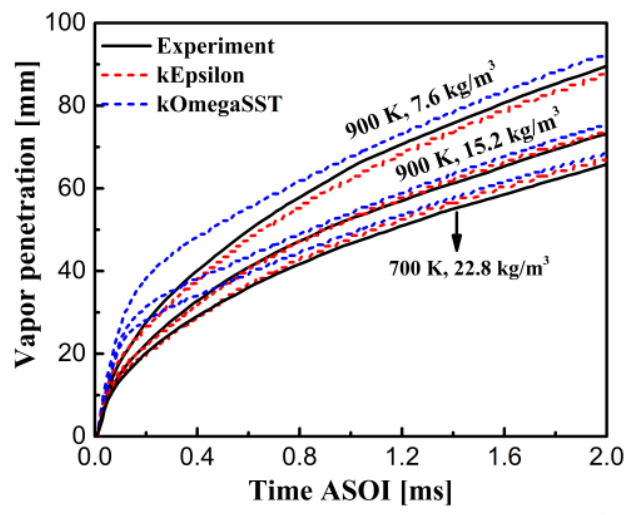

Figure 7. Measured and computed vapor penetration for three different ambient conditions.

To provide a quantitative assessment of the fuel-air distribution, which is the fundamental prerequisite for combustion simulations, Fig. 8(a) and 8(b) compare the radial distributions of mixture fraction at two axial positions ( 25 and $45 \mathrm{~mm}$ from the injector nozzle) at 1.5 ms ASOI, and Fig. 8(c) presents the comparison between experimental and computed axial mixture fraction distribution at the same time [64]. It is possible to see that both turbulence models are capable of capturing quantitative and qualitative mixture fraction distributions in the quasi-steady phase of the jet. Differences between the distributions predicted by $k-\varepsilon$ and $k-\omega$ SST models occur along the centerline of the spray, approximately from $10 \mathrm{~mm}$ to 15 $\mathrm{mm}$ from the nozzle. This represents the region where liquid fuel may be found, and unfortunately validation is not possible due to the lack of measured data. A possible explanation for such difference can be found in the comparison of axial velocity along the centerline of spray as shown in Fig. 9(c). The axial velocity in the vicinity of nozzle mainly depends on the exchange of mass and momentum between liquid and gas phase. In this case, the higher axial velocity predicted by $k-\omega$ SST model from $0 \mathrm{~mm}$ to $10 \mathrm{~mm}$ where liquid still exists, indicates the faster particles penetration, which could enhance the breakup and evaporation processes of liquid fuel, and result in a richer mixture downstream. For the sake of completeness, the measured and computed axial and radial velocities at $25 \mathrm{~mm}$ and $45 \mathrm{~mm}$ from the injector are also illustrated in Fig. 9(a) and 9(b), respectively. The computed results from both turbulence models with respect to axial velocity are in good agreement with measured profiles [64], and the general trends of radial velocity are captured. 

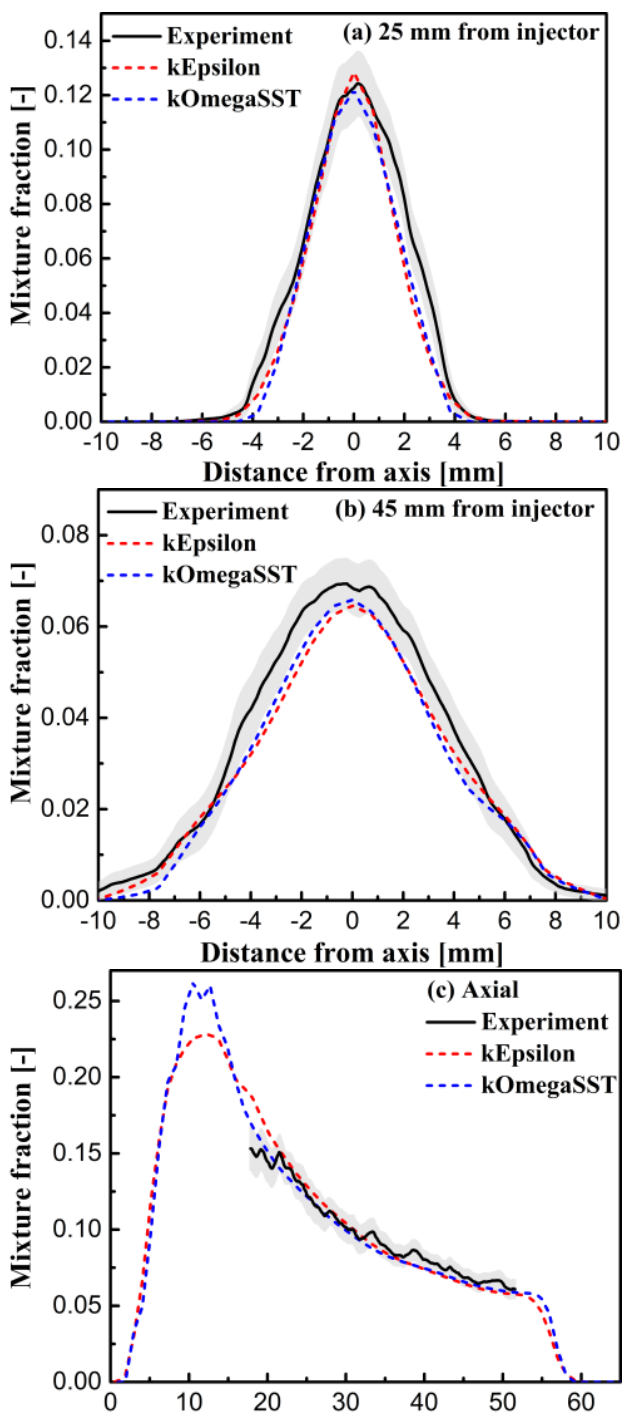

Axial distance from injector $[\mathrm{mm}]$

Figure 8. Comparison between experimental and computed radial mixture fraction distribution at (a) $25 \mathrm{~mm}$ and (b) $45 \mathrm{~mm}$ from the injector and (c) axial mixture fraction distribution at $1.5 \mathrm{~ms}$. Grey shaded region: measured standard deviation.

Following the successful validation of a non-reacting single injection, the two numerical setups are adopted and further assessed for simulating Spray A multiple injections $(0.5 \mathrm{~ms} / 0.5-\mathrm{ms}$ dwell/ $/ 0.5 \mathrm{~ms})$. Fig. 10 compares the measured and computed vapor penetrations from the first and second injections at a $900-\mathrm{K}$ and $22.8-\mathrm{kg} / \mathrm{m}^{3}$ ambient. Due to the identical ambient conditions and injection parameters, the first injection does not differ from the single $0.5-\mathrm{ms}$ injection Spray A until circa $1 \mathrm{~ms}$ ASOI. In this case, more attention should be paid to the second injection. It was highlighted by Skeen et al. [46] that the higher turbulence and faster penetration due to the slipstream effect of a second injection could enhance the rate of mixing, having the potential to shorten its ignition delay under reactive conditions. To this end, correctly predicting such slipstream effect is of particular interest, which unfortunately is overestimated by both $k-\varepsilon$ and $k-\omega$ SST models after about $1.2 \mathrm{~ms}$ as displayed in Fig. 10. Together with the observation that the initial penetration of the second injection depends on the accuracy of predicting the liquid jet, it is possible to conclude that the overprediction of the slipstream effect might be related to the prediction of momentum transfer to the gas phase. This aspect suggests that a separate

Page 7 of 17 calibration of spray model constants for the first and second injection might be necessary to capture the vapor penetrations of multiple injections more accurately.
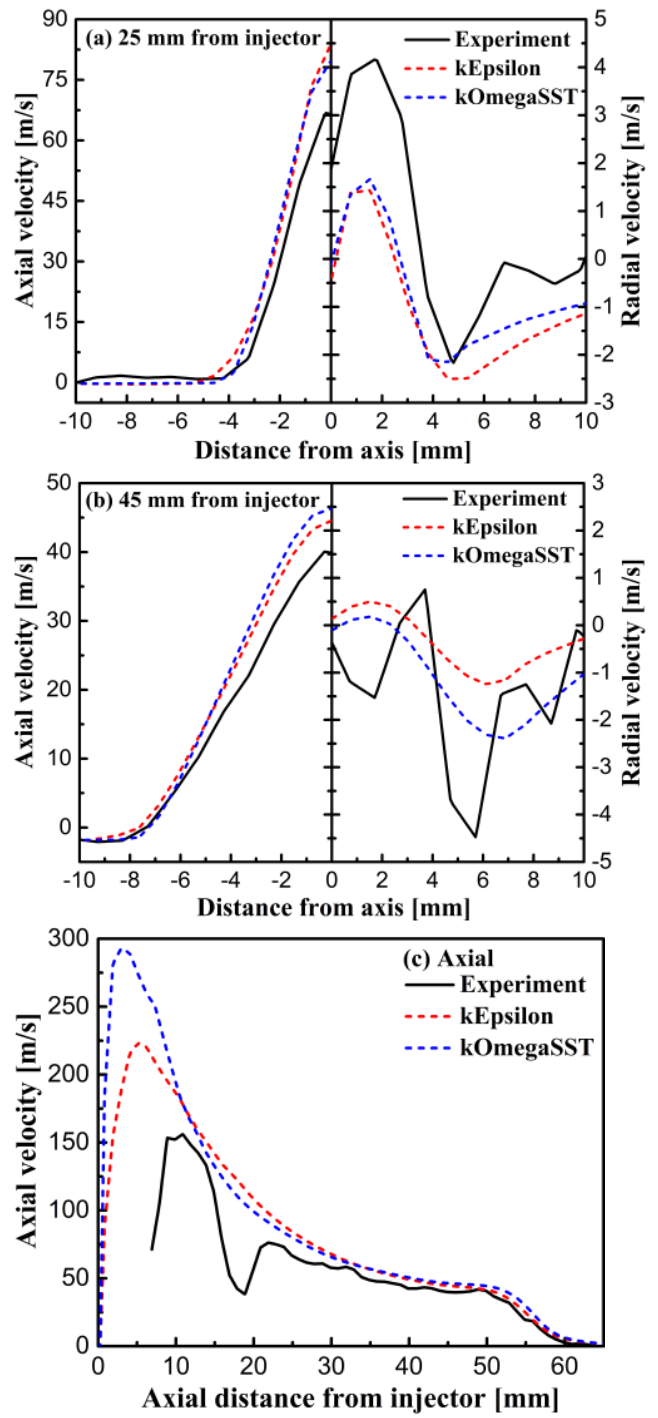

Figure 9. Comparison between experimental and computed axial and radial velocities at (a) $25 \mathrm{~mm}$ and (b) $45 \mathrm{~mm}$ from the injector and (c) axial velocity along the centerline of the spray at $1.5 \mathrm{~ms}$.

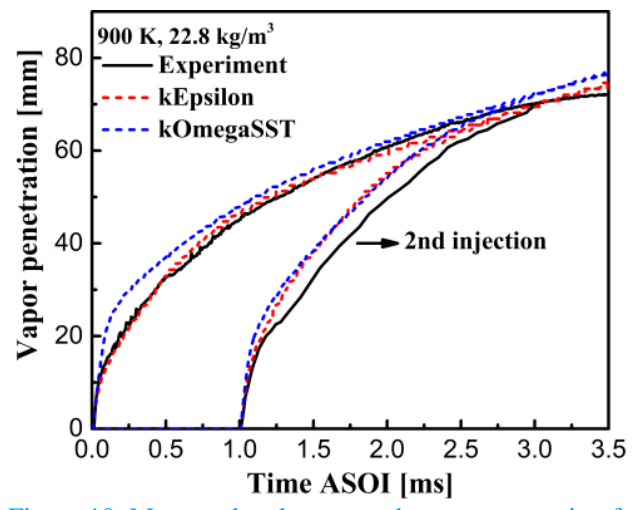

Figure 10. Measured and computed vapor penetration for multiple injections (0.5 ms/0.5-ms dwell/0.5 ms) under non-reacting condition. 
Time sequences of mixture fraction contours predicted by $k-\varepsilon$ and $k-\omega$ SST models are presented in Fig. 11 with white lines depicting the stoichiometric mixture fractions and the border of the spray $(\mathrm{Z}=$ 0.001 ), to give a detailed comparison of fuel-air mixing process. As previously discussed for the inert single injection, the $k-\omega$ SST model initially overpredicts vapor penetration due to the faster transient liquid penetration, which can also be observed in split injections during the first $(0.3 \mathrm{~ms})$ and second $(1.2 \mathrm{~ms})$ pulses. Besides, a narrow spray distribution but larger region inside stoichiometric contour line can be seen in $k-\omega$ SST case. This is mainly because the $k-\omega$ SST model predicts higher axial velocity along the central axis, pushing richer mixtures further downstream from the nozzle with less radial dispersion. This presence of richer zones could affect the ignition delay prediction and become essential for low ambient temperature cases with long ignition delay close to the limit of ignitibility as also stated by Blomberg et al. [23], which will be discussed below.

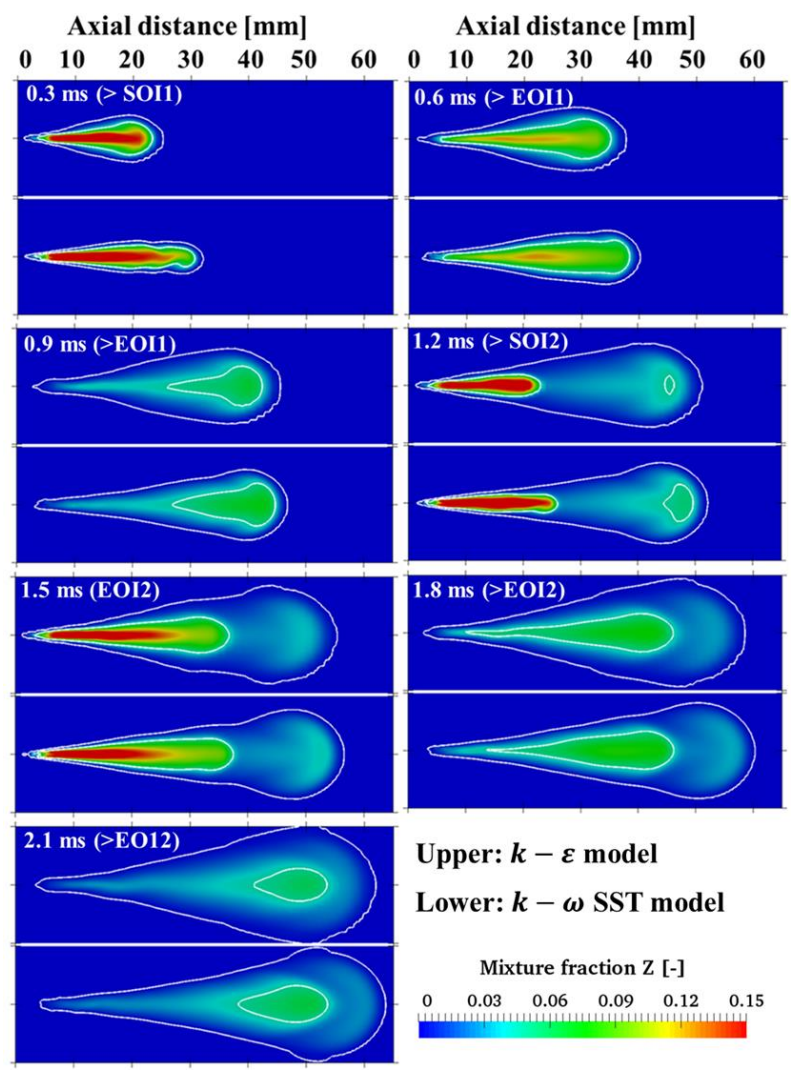

Figure 11. Mixture fraction distribution from 0.3 to $2.1 \mathrm{~ms}$. The upper part indicates $k-\varepsilon$ model and the lower part represents $k-\omega$ SST model. The border of the spray and a contour line of stoichiometric mixture fraction are shown in solid white lines.

\section{Reacting conditions}

Validation and combustion of RIF and TFPV combustion models in conjunction with $k-\varepsilon$ and $k-\omega$ SST turbulence models for reacting conditions are performed following the achieved accuracy in inert multiple injection simulations. The oxidation of n-dodecane was modeled using the mechanisms proposed by Frassoldati et al. [65, 66] and Yao et al. [67], consisting of 130 species and 2323 reactions and 54 species and 269 reactions, respectively. Simulated operating conditions using the same splitting strategy $(0.5 \mathrm{~ms} / 0.5-\mathrm{ms}$ dwell/0.5 $\mathrm{ms}$ ) are reported in Tab. 1, including the variation of ambient temperature.

Page 8 of 17
Table 1. Simulated reacting Spray A operating conditions.

\begin{tabular}{lllll}
\hline & $\begin{array}{l}\text { Ambient } \\
\text { temperature }\end{array}$ & $\begin{array}{l}\text { Ambient } \\
\text { density }\end{array}$ & $\begin{array}{l}\text { Injection } \\
\text { pressure }\end{array}$ & Injector \\
\hline 1 & $900 \mathrm{~K}$ & $22.8 \mathrm{~kg} / \mathrm{m}^{3}$ & $1500 \mathrm{bar}$ & $\# 210370[46]$ \\
2 & $800 \mathrm{~K}$ & $22.8 \mathrm{~kg} / \mathrm{m}^{3}$ & $1500 \mathrm{bar}$ & $\# 210370$ \\
3 & $750 \mathrm{~K}$ & $22.8 \mathrm{~kg} / \mathrm{m}^{3}$ & $1500 \mathrm{bar}$ & $\# 210370$ \\
4 & $900 \mathrm{~K}$ & $22.8 \mathrm{~kg} / \mathrm{m}^{3}$ & $1500 \mathrm{bar}$ & ECN\#306.22 [47] \\
\hline
\end{tabular}

The setup for the TFPV table is reported in Tab. 2. The unsteady diffusion flame calculations were performed only within a 600-1350 $\mathrm{K}$ temperature range, and later the table would be extended to $400 \mathrm{~K}$ with values taken from the homogeneous chemistry table. 33 points in the mixture fraction space and three pressure levels taking into account the minimum and maximum ones encountered in the selected operating conditions were considered. The chosen values of the stoichiometric scalar dissipation rate follow a log-law and discretization of the TFPV table was mainly a compromise between accuracy and computational costs.

Table 2. Chemistry table discretization.

\begin{tabular}{ll}
\hline Temperature [K] & $400,450,500,550600,650,700,750$, \\
& $800,850,900,1000,1050,1150,1250$, \\
& 1350 \\
\hline Pressure [bar] & $45,55,65$ \\
\hline \multirow{2}{*}{ Equivalence ratio } & $0,0.2,0.4,0.5,0.6,0.7,0.75,0.8,0.85$, \\
& $0.9,0.95,1,1.05,1.1,1.15,1.2,1.25$, \\
& $1.3,1.35,1.4,1.5,1.6,1.7,1.8,1.9,2$, \\
& $2.2,2.4,2.6,2.8,3,3.5,1 \mathrm{e} 15$ \\
\hline Mixture fraction segregation & $0,0.001,0.005,0.01,0.05,0.1,1$ \\
\hline Scalar dissipation rate $[1 / \mathrm{s}]$ & $0,1,3,7,20,55,100$ \\
\hline
\end{tabular}

\section{Combustion models: RIF vs TFPV}

The computed high-temperature ignition delays from RIF and TFPV models are reported in Tab. 3 , and compared against experimental measurements [46] at different ambient temperature conditions. The first ignition delay from simulations is defined as the time from start of injection to the time where the maximum rate of maximum temperature rise in the domain occurs. However, for the second injection, it is calculated as the time delay from start of second injection to the time $20 \%$ rise in apparent heat release rate (AHRR) relative to the minimum value after the first ignition event following [46], or relative to the minimum value after the second cool flame in the RIF case. The choice of a different criterion for the RIF model is to avoid the calculated ignition delay occurring during the cool flame where high-temperature combustion does not happen. Such concern is mainly because the absence of flamelet interaction leads to independent evolutions of two flamelets and combustion events, predicting the AHRR trace from the second injection in a similar way to the first one. This then shows evident cool flame behavior as illustrated in Fig. 12 and 13, which compare the experimental and computed AHRR for $800-\mathrm{K}$ and $900-\mathrm{K}$ ambient temperature, respectively. Looking at the measured ignition delays at an $800-\mathrm{K}$ and $900-\mathrm{K}$ ambient, the values from the second injection are reduced by approximately a factor of two compared to the first injection, which could be attributed to two factors: 1 . faster mixing of second injection due to the reduced local density and slipstream effect; 2 . the 
hot combustion products including radical species remaining from the first injection. However, only the effect of faster mixing is considered in RIF model, whereas neglecting the interaction between flamelets makes it unable to take into account the second factor, causing a significant overprediction in the second ignition delay. This limitation could be overcome in the TFPV model by means of introducing a progress variable. This contains the information of reactants and products mass fractions as well as gas temperature, allowing to take the thermo-chemical field remaining from the first combustion event into consideration. As a consequence, the TFPV model predicts the second ignition delay with an adequate accuracy, and captures the experimental AHRR profiles appropriately.

Table 3. Computed ignition delay times from RIF and TFPV.

\begin{tabular}{llll}
\hline Ambient T & Experiment [ms] & RIF [ms] & TFPV [ms] \\
\hline $900 \mathrm{~K}$ & $0.33 \pm 0.03 / 0.17 \pm 0.01$ & $0.39 / 0.23$ & $0.46 / 0.17$ \\
\hline $800 \mathrm{~K}$ & $0.88 \pm 0.09 / 0.34 \pm 0.06$ & $0.83 / 0.71$ & $0.79 / 0.23$ \\
\hline $750 \mathrm{~K}^{*}$ & $2.0 \pm 0.05$ & -- & -- \\
\hline
\end{tabular}

*No distinct high-temperature ignition event on the basis of maximum temperature are predicted in simulations for the $750-\mathrm{K}$ ambient temperature.

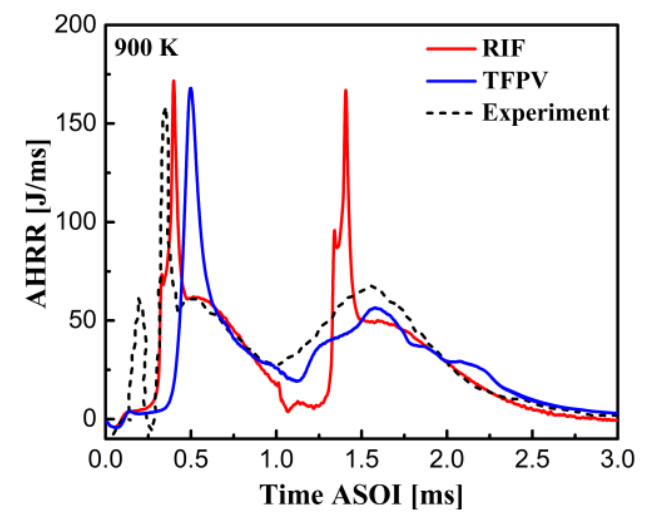

Figure 12. Comparison between experimental [46] and computed apparent heat release rate for a $900-\mathrm{K}$ ambient temperature.

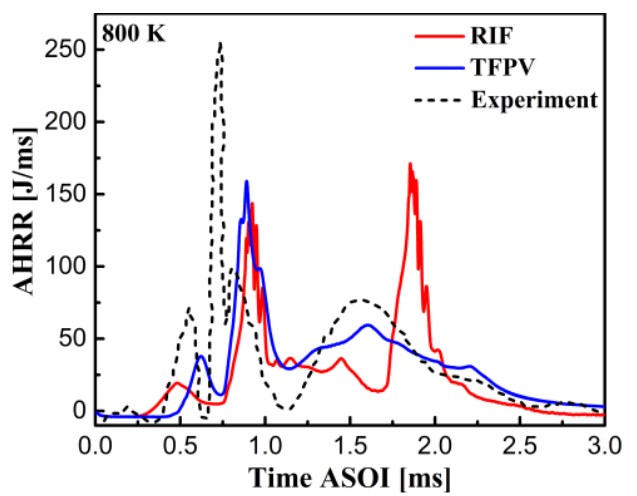

Figure 13. Comparison between experimental [46] and computed apparent heat release rate for an $800-\mathrm{K}$ ambient temperature.

To provide a comprehensive validation of combustion models, it is essential to assess their capabilities of capturing the cool flame characteristics and tracking low-temperature reaction products such as formaldehyde $\left(\mathrm{CH}_{2} \mathrm{O}\right)$. To this end, the time sequences of formaldehyde PLIF images measured by Skeen et al. [46] are used to validate the computed spatial and temporal results from RIF and TFPV models for $900-\mathrm{K}$ and $800-\mathrm{K}$ ambient. For an ambient temperature of $900 \mathrm{~K}$, it was highlighted in [46], the images suffered from interference of rich combustion products, such as polycyclic Page 9 of 17 aromatic hydrocarbons (PAH) and soot incandescence. For this reason, the computed mass fractions of acetylene $\left(\mathrm{C}_{2} \mathrm{H}_{2}\right)$ as a soot precursor, are also displayed in Fig. 14, where the simulation plots are split into two parts (upper panel: $\mathrm{CH}_{2} \mathrm{O}$; lower panel: $\mathrm{C}_{2} \mathrm{H}_{2}$ ) and the border of spray as well as the stoichiometric mixture fraction are depicted by solid white lines. The dashed lines in PLIF images illustrate the lift-off location and the spray penetration of second injection. Focusing on the ignition and cool flame characteristics, several observations and interpretations from authors can be summarized as follows:

1. At $0.69 \mathrm{~ms}$, a distinction between $\mathrm{CH}_{2} \mathrm{O}$ (near the injector) and PAH (downstream, around $35-40 \mathrm{~mm}$ ) is observed in experiments. The TFPV model correctly predicts the $\mathrm{CH}_{2} \mathrm{O}$ in the upstream of $\mathrm{C}_{2} \mathrm{H}_{2}$ regions indicating that the lowtemperature combustion recession takes place. However, in the further downstream region $(20-35 \mathrm{~mm})$, the TFPV model also shows the presence of $\mathrm{CH}_{2} \mathrm{O}$. A possible explanation could be the overprediction of the first ignition delay, as reported in Tab. 3 and Fig. 12, resulting in the late consumption of lowtemperature products.

2. At $0.99 \mathrm{~ms}$ and $2.09 \mathrm{~ms}$, experiments only show PAH and soot and this is correctly predicted by simulations as only $\mathrm{C}_{2} \mathrm{H}_{2}$ is present. However, these simulations show longer $\mathrm{C}_{2} \mathrm{H}_{2}$ tails, similar to the results by Blomberg et al. [23], and lower intensity indicating that $\mathrm{PAH}$ is shorter lived in simulations. This agrees with the advanced soot consumption which will be shown in Fig. 15.

3. At $1.09 \mathrm{~ms}$, right after the start of the second injection, the TFPV model predicts more distinct $\mathrm{CH}_{2} \mathrm{O}$ in the near nozzle region due to the fact that fuel is injected into the combustion products remaining from the first injection, where the progress variable is high, promoting the low-temperature or even the high-temperature ignition to take place. Regarding to the RIF model, again the ignorance of flamelet interaction limits its capability to consider the effect of radical species.

4. At $1.49 \mathrm{~ms}$, from the planar contours of $\mathrm{C}_{2} \mathrm{H}_{2}$ representing the high-temperature combustion, it is possible to see that the lift-off length is correctly predicted by the TFPV model considering the local flow conditions, whereas flame is anchored at the exit of nozzle in RIF case since only single flamelet is used to characterize each injection event.

5. After each combustion event (0.99-1.09 ms, and $2.09 \mathrm{~ms})$, a larger region inside stoichiometric contour lines can be seen in TFPV simulations. This might be related to the previous point. In particular, more fuel in the vicinity of nozzle remains unburned due to the presence of the lift-off length, which then propagates downstream by convection and diffusion, leading to this larger region.

For this operating point, the experimental time-resolved total soot mass is available [32], by which it is possible to understand the capability of proposed models in predicting soot emissions for the multiple injection case. This is presented in Fig. 15, together with the temporal evolution of simulated total soot mass. The shaded region demonstrates the shot-to-shot variation among four independent experiments obtained with the high-speed DBIEI diagnostic [33]. It can be observed from ensemble averaged data that the second injection produces a factor of four more soot than the first injection due to the advanced ignition, which occurs near the liquid length where the local mixture is rich. This trend is well reproduced by simulations. However, to predict the correct amount of soot mass, different soot tuning parameters for the surface growth step are used for TFPV and RIF models, while the other steps were kept the same. 
In particular, the pre-exponential factor of reaction rate constant used for TFPV is three times higher than the one for RIF. Reasons for such high value in TFPV case might be related to two aspects: first, neglecting the contribution from rich mixtures $(\phi \geq 3)$ to autoignition could also limit the production of soot. Secondly, not all the fuel is oxidized in TFPV case, due to the limitation of ignition in fuel rich regions and the use of tabulation. In this case, a future work will be surely dedicated to assess the sensitivity of combustion models to soot tuning parameters together with more detailed validation with optical data.

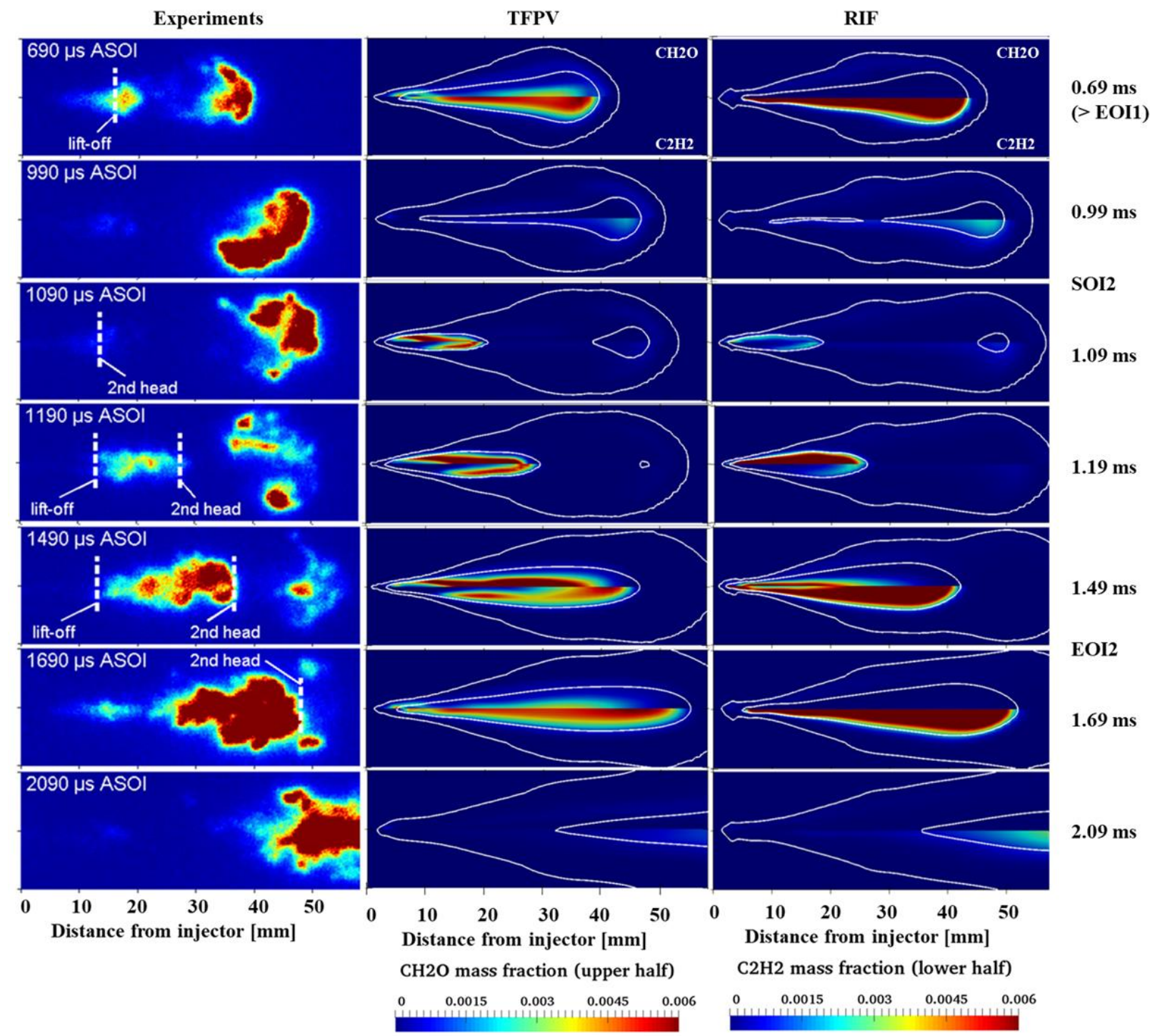

Figure 14. Comparison between formaldehyde PLIF results from experiments [46] and planar contours predicted by TFPV and RIF at an ambient of $900 \mathrm{~K}$. Two solid white lines represent border of the spray and stoichiometric mixture fraction. The planar contours are split into two parts: $\mathrm{CH}_{2} \mathrm{O}$ (upper half) and represents the $\mathrm{C}_{2} \mathrm{H}_{2}$ (lower half) 


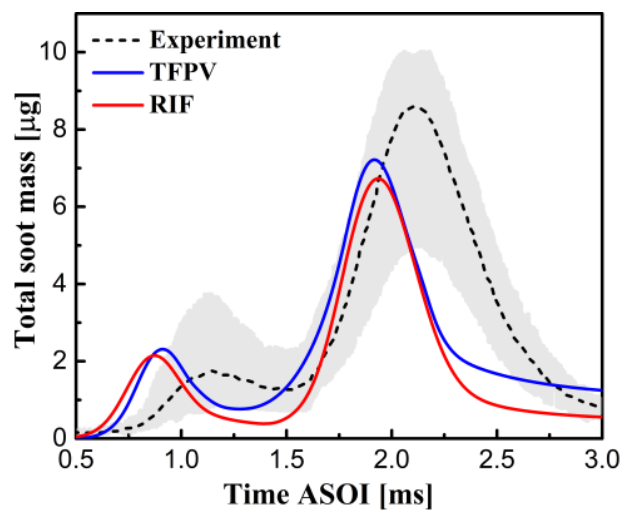

Figure 15. Comparison between measured [33] and computed total soot mass at an ambient temperature of $900 \mathrm{~K}$. Grey shading region: measurement standard deviation.

For an ambient temperature of $800 \mathrm{~K}$, the comparison between measured formaldehyde PLIF images and computed mass fraction of $\mathrm{CH}_{2} \mathrm{O}$ is displayed in Fig. 16. The dashed lines in experiments represent the head of second spray, and two solid white lines are plotted in simulation results to illustrate the border of spray and contour line of stoichiometric mixture fraction. Note that only $\mathrm{CH}_{2} \mathrm{O}$ is plotted, since such low-temperature conditions are free of soot formation [46]. However, there is still some evidence of soot in simulations, although the quantity is rather low. Three main observations are made:
1. At $0.89 \mathrm{~ms}$, the experimental PLIF image shows $\mathrm{CH}_{2} \mathrm{O}$ exists in a large area along the central plane of the spray axis, which appears to be consumed at $0.99 \mathrm{~ms}$, indicating the hightemperature ignition takes place. However, this is not presented in simulations at these instants since the consumption has almost completed due to the underestimation of ignition delays, as shown in Tab. 3 and Fig. 13.

2. At $0.99 \mathrm{~ms}, 1.79 \mathrm{~ms}$ and $2.09 \mathrm{~ms}$, the TFPV model shows that $\mathrm{CH}_{2} \mathrm{O}$ remains upstream of the lift-off location, revealing low temperature combustion recession back towards to the nozzle, which is visualized in experiments at $0.99 \mathrm{~ms}$ by amplifying the fluorescence signal by a factor of 10 [46]. However, RIF is not able to predict such phenomena, again because of the single flamelet formulation for each injection event, making it impossible to predict the flame stabilization process and the likelihood of subsequent combustion recession.

3. During and right after the second injection $(1.29 \mathrm{~ms}, 1.39 \mathrm{~ms}$ and $1.59 \mathrm{~ms}$ ), when the high-temperature ignition has not commenced, it can be seen that the evident presence of $\mathrm{CH}_{2} \mathrm{O}$ happens earlier in TFPV case relative to the experiment, resulting in the underestimation of the second ignition delay as reported in Tab. 3. A possible explanation could be the overprediction of the second spray penetration, where the hightemperature combustion products downstream could accelerate the cool flame reactions. As previously discussed in the Fig. 10 (inert injections), probably the recalibration of spray models is necessary for the second injection, especially under less reactive conditions.
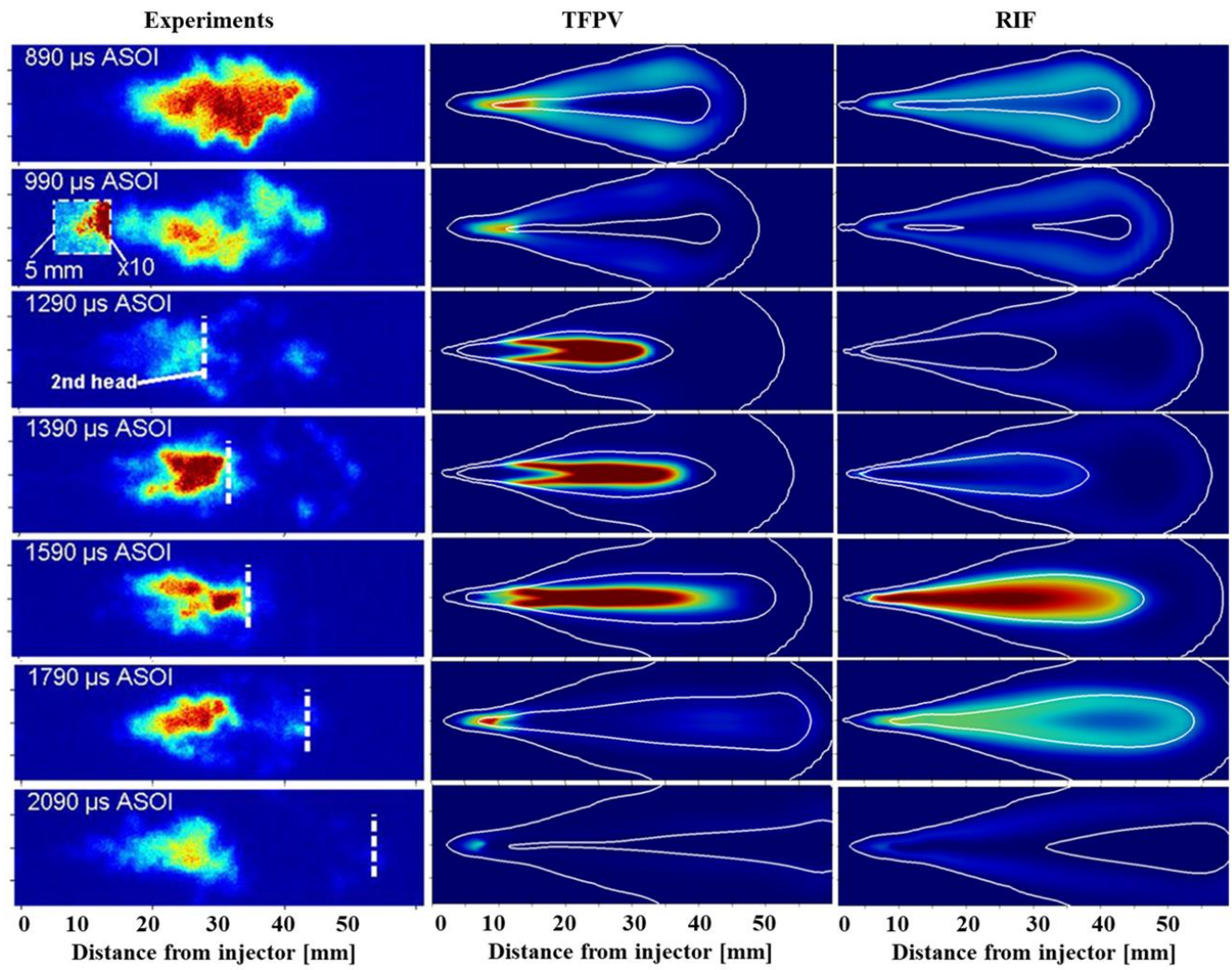

$0.89 \mathrm{~ms}$

(> EOI1)

$0.99 \mathrm{~ms}$

SOI2

$1.29 \mathrm{~ms}$

$1.39 \mathrm{~ms}$

EOI2

$1.59 \mathrm{~ms}$

CH2O mass fraction

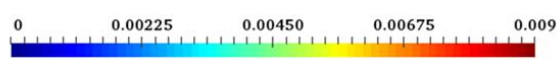

Figure 16. Comparison between formaldehyde PLIF results from experiments [46] and planar contours predicted by TFPV and RIF for at an ambient temperature of $800 \mathrm{~K}$. Two solid white lines represent borders of the spray and stoichiometric mixture fraction. 
Returning to Tab. 3, at a 750-K ambient the high-temperature ignition occurs around $2 \mathrm{~ms}$ and experimentally the first injection does not exhibit a distinct high-temperature ignition event. The measured and computed AHRR curves for 750-K ambient are compared in Fig. 17. Unfortunately, no evident high-temperature ignition event after the second injection is presented in simulation results from TFPV and RIF models. This could be explained by two intertwined aspects: chemistry and mixing. Most likely, the employed chemical mechanism is not suitable for very lean and low-temperature operating conditions. This may overpredict the ignition delay and result in an environment which is too lean to ignite under such condition.

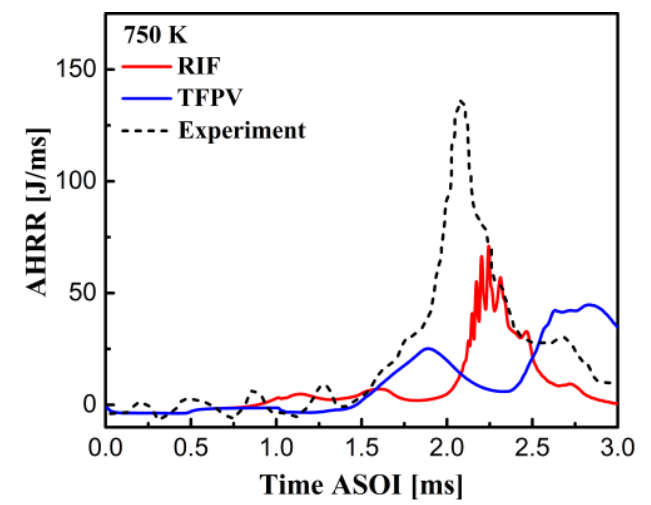

Figure 17. Comparison between experimental [45] and computed apparent heat release rate for a $750-\mathrm{K}$ ambient temperature.
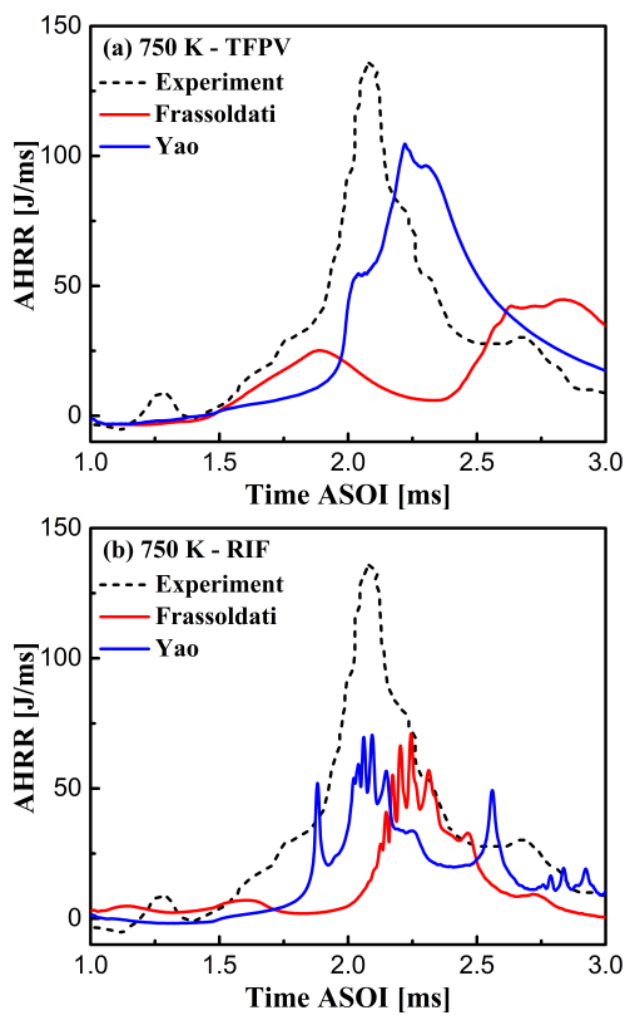

Figure 18. Comparison between 750-K experimental and computed apparent heat release rate from (a) TFPV and (b) RIF using different chemical mechanisms.

Table 4. Computed ignition delay times from different chemistry mechanisms

\begin{tabular}{llll}
\hline Ambient T & Experiment & Yao & Frassoldati \\
\hline
\end{tabular}

Page 12 of 17

\begin{tabular}{llllll}
\hline \multirow{2}{*}{$900 \mathrm{~K}$} & \multirow{2}{*}{$0.33 / 0.17$} & RIF & $0.36 / 0.23$ & $0.39 / 0.23$ & $\mathrm{~ms}$ \\
& & TFPV & $0.30 / 0.17$ & $0.46 / 0.17$ & $\mathrm{~ms}$ \\
\hline \multirow{2}{*}{$800 \mathrm{~K}$} & \multirow{2}{*}{$0.88 / 0.34$} & RIF & $0.78 / 0.66$ & $0.83 / 0.71$ & $\mathrm{~ms}$ \\
& & TFPV & $0.82 / 0.27$ & $0.79 / 0.23$ & $\mathrm{~ms}$ \\
\hline \multirow{2}{*}{$750 \mathrm{~K}$} & \multirow{2}{*}{$2.0 \pm 0.05$} & RIF & -- & -- & $\mathrm{ms}$ \\
& & TFPV & 2.21 & -- & $\mathrm{ms}$ \\
\hline
\end{tabular}

To investigate the influence of chemistry, a skeletal mechanism of ndodecane proposed by Yao et al. [67] with optimized semi-global low-temperature chemistry is adopted, which has been extensively studied by Payri et al. [68] in Spray A simulations at different ambient conditions, showing satisfactory agreement with experiments. The comparison between experimental and computed AHRR curves from these two chemical mechanisms for $750 \mathrm{~K}$ is presented in Fig. 18. It should be highlighted that for the Yao case, the equivalence ratio range of TFPV tables was extended to $\phi=0.05$ in consideration of the lean mixture due to the long ignition delay. It is evidenced that simulation results are remarkably improved in terms of combustion phase, but still no evident high-temperature ignition takes place in the RIF case. Possible reasons could be related to description of mixing and ignorance of flamelet interaction, which are of particular interest to be further investigated in future work. For the sake of completeness, Tab. 4 summarizes the ignition delays for all these three cases computed from Yao and Frassoldati mechanisms. In general, the impact of chemistry on ignition delay prediction cannot be neglected, and Yao mechanism provides a better prediction in our present work. Details on the influence of chemical mechanisms on the turbulent spray flames are explained in ref. [68], but will not be discussed in this paper.

With respect to mixing, apart from the necessity of separate spray calibration for the second injection, the choice of turbulence model could also impact the ignition delay prediction as discussed in Fig. 11. Due to the fact that richer mixtures are present in the downstream region of the spray in the $k-\omega \mathrm{SST}$ case, it can be expected that using this turbulence model could to some extent improve the ignition delay prediction at $750 \mathrm{~K}$. Before application to lowtemperature cases, the capability of the $k-\omega$ SST model to predict the $900-\mathrm{K}$ case should be extensively assessed in terms of ignition characteristics and flame structures. This will be presented in the following section.

\section{Turbulence models: $k-\varepsilon$ vs $k-\omega$ SST}

In Tab. 5, the computed ignition delay times from $k-\omega$ SST and $k-\varepsilon$ turbulence models with both TFPV and RIF combustion models are compared to measured values from [47]. The comparison between AHRR curves from these two turbulence models is also displayed in Fig. 19. The impact of turbulence models is more evident in the RIF case, where $k-\omega$ SST predicts longer ignition delays for both the first and second injection. Explanations can be found in Fig. 20, displaying the computed evolution of average stoichiometric scalar dissipation rate from these two turbulence models. It can be seen that flamelets in $k-\omega$ SST cases generally undergo higher average stoichiometric scalar dissipation rates. This governs the evolution of species and energy in mixture fraction space, leading to longer ignition delay relative to the $k-\varepsilon$ model. To deepen the interpretation, returning to Fig. 8(c), the much higher mixture fraction gradient can be seen along the spray axis in the $k-$ $\omega$ SST case, causing a faster generation of mixture fraction variance with a consequently higher scalar dissipation rate. However, this 
aspect could not postpone the ignition events in the TFPV case, which is mainly due to two factors: (1) the TFPV approach could take into account the local distribution of scalar dissipation rate; (2) the higher scalar dissipate rate predicted by $k-\omega$ SST model occurs in the near nozzle region, accompanying very rich mixtures that cannot be ignited. In fact, slightly earlier high temperature ignitions are predicted by the $k-\omega \mathrm{SST}$ and TFPV model combination, as a result of faster penetration and mixing.

Table 5. Computed ignition delay times for $900 \mathrm{~K}$ using $k-\omega \mathrm{SST}$ and $k-\varepsilon$ models.

\begin{tabular}{lllll}
\hline Experiment & CFD & $k-\omega$ SST & $k-\varepsilon$ & \\
\hline \multirow{2}{*}{$0.37 \pm 0.1 / 0.11 \pm 0.08$} & RIF & $0.48 / 0.36$ & $0.39 / 0.24$ & $\mathrm{~ms}$ \\
\cline { 2 - 5 } & $\mathrm{TFPV}$ & $0.44 / 0.15$ & $0.47 / 0.16$ & $\mathrm{~ms}$ \\
\hline
\end{tabular}
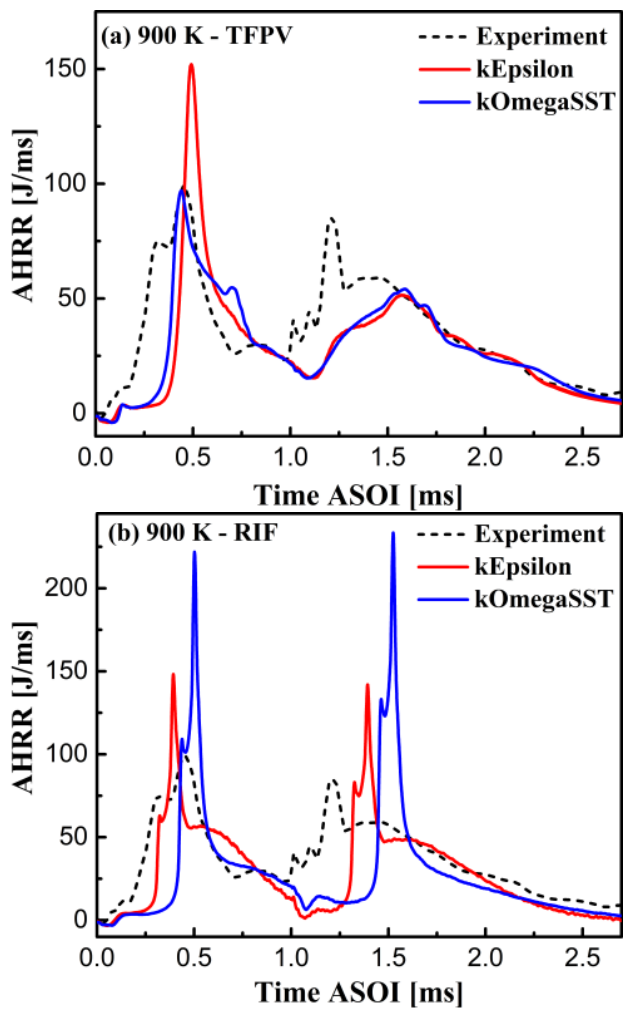

Figure 19. Comparison between experimental and computed apparent heat release rate from (a) TFPV and (b) RIF using different turbulence models.

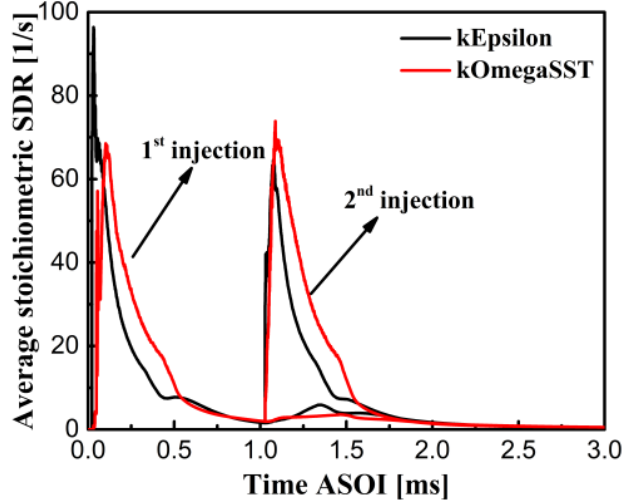

Figure 20. Computed evolution of the averaged stoichiometric scalar dissipation rate of two injection events using $k-\omega$ SST and $k-\varepsilon$ models

The so-called $I-x-t$ (intensity - axial distance - time) plot is used to qualitatively compare the flame structure from measurements and simulations. Such a plot is calculated by integrating $\mathrm{OH}^{*}$ chemiluminescence data from experiments or $\mathrm{OH}$ mass fraction from CFD along the symmetry axis, according to Eq. (26):

$I(x, t)=\int_{0}^{R} I(x, r, t) d r$

where $x$ is the intensity axial direction, $r$ is the radial direction, and $R$ is the radial limit. Then intensity $I$ is plotted against the time after start of injection and axial distance. Following this approach, aspects such as ignition delay time, lift-off length and combustion recession, as well as the flame tip and foot locations can be studied in the $I-$ $x-t$ plot. Fig. 21 depicts the comparison of such plots from experiment and simulations at a 900-K ambient temperature. In Fig. 21 (a), various combustion features are exhibited in the experimental $I-x-t$ plot, in particular, combustion recessions are identified by dotted white circles, ignition delays and lift-off lengths are illustrated in dashed green and solid yellow lines, respectively. The intensity at which $0.015<I^{\text {normlized }}<0.025$ representing the outer contour of experimental data is shown in white line. This contour has also been plotted in Fig. 21(b) - (e), which show simulation results from $k-\omega$ SST and $k-\varepsilon$ turbulence models in conjunction with TFPV and RIF approaches. The experimental contours are intended to aid in the assessment and evaluation of the performance of different modeling methodologies. Comparing the TFPV to the RIF approach, RIF limitations in terms of describing the flame stabilization and prediction of the ignition delay of the second injection, are successfully overcome by TFPV model as shown in Fig. 21(b) and (c), in which high-temperature combustion recession is also observed, agreeing with experimental data. Regarding to the turbulence models, impacts on the lift-off length are clearly shown in Fig. 21(b) and (c) using the TFPV model. Specifically, the flame is stabilized further from the nozzle in the $k-\omega$ SST case, as a consequence of higher scalar dissipation rate and richer mixtures in the vicinity of the injector. Moreover, the computed flame-tip penetration is barely affected in all cases and very similar to the experimental one, whereas the flame-foot of $k-\omega$ SST cases is found further downstream from the injector, yielding better agreement with measurements. This makes sense since these two parameters, flametip and foot locations, are indications of velocity field, where $k-\omega$ SST and $k-\varepsilon$ models differ in the tail rather than the tip of spray regrading to the prediction of velocity. 

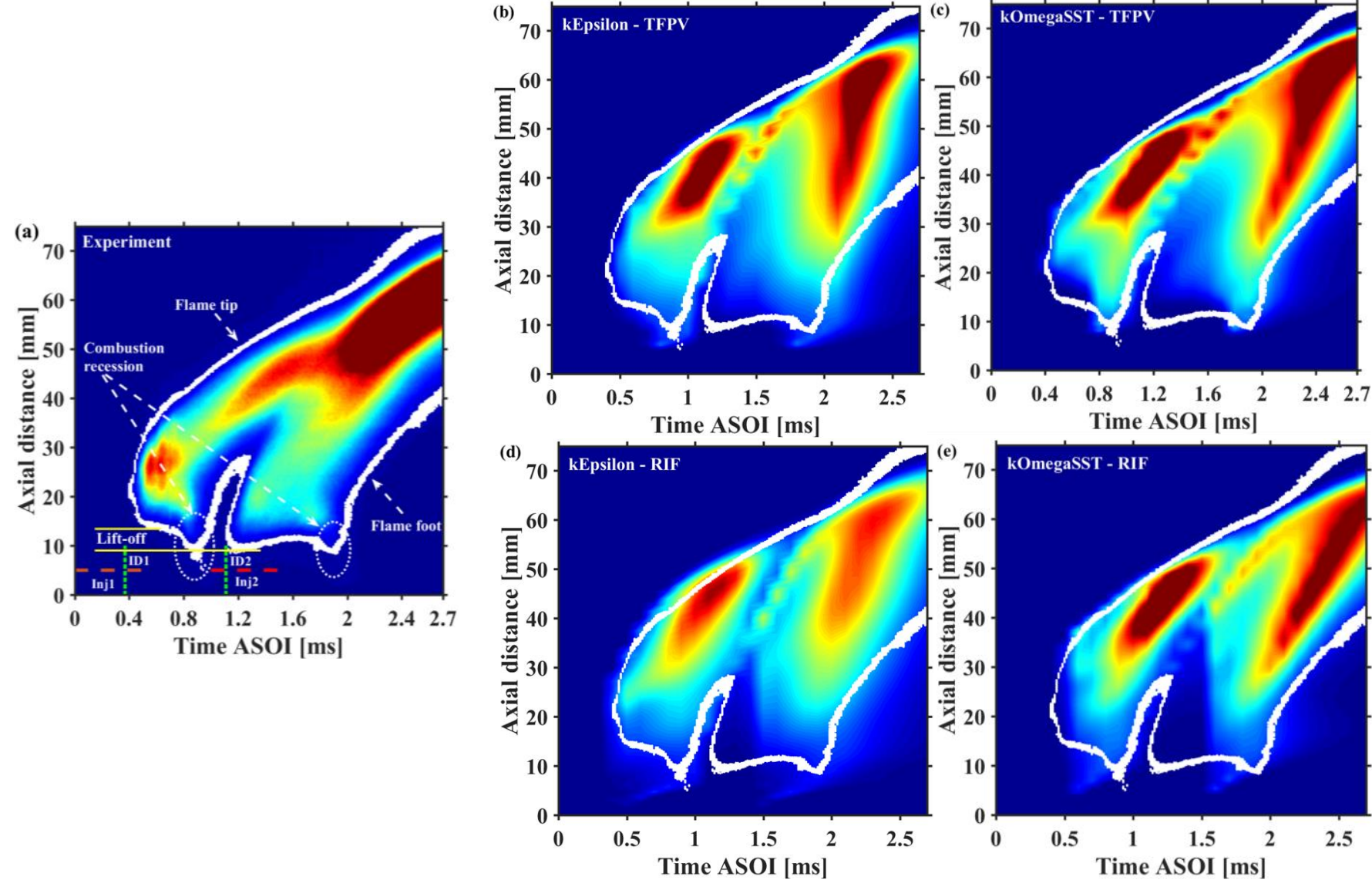

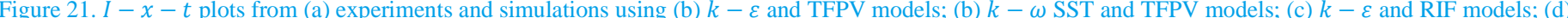

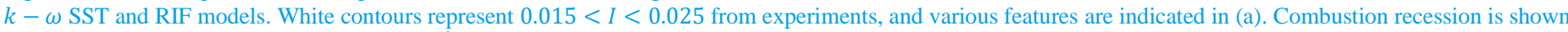
in the white circle; ignition delays of $1^{\text {st }}$ and $2^{\text {nd }}$ injection and lift-off lengths are identified by dashed green and solid yellow lines, respectively.

Last but not least, some considerations about the computational time are discussed. In the framework of the $k-\varepsilon$ model, one reacting simulation using the RIF model was completed in approximately 13.8 hours on 12 cores equipped with Intel(R) Xeon(R) CPU E5-2630 v2 processors, while 23.5 hours on the same number of cores were required to complete the simulation using the TFPV model. In addition, it is important to consider that 2 hours on 16 cores were needed to generate the TFPV table and approximately 3.5 hours on 4 cores were spent on chemistry table generation on the basis of 0-D homogeneous reactor calculations. Concerning $k-\omega$ SST cases, the use of a very fine mesh and large number of cells increased the CPU time by a factor of 3 compared to the $k-\varepsilon$ cases. Therefore, reducing the mesh dependency of spray models is of vital importance for applying $k-\omega \mathrm{SST}$.

\section{Conclusions}

The main objective of this work is a detail comparison of different turbulence models and combustion approaches for modeling the $\mathrm{n}$ dodecane multiple injection Spray A $(0.5 \mathrm{~ms} / 0.5-\mathrm{ms}$ dwell $/ 0.5 \mathrm{~ms})$. In particular, two turbulence models, $k-\varepsilon$ and $k-\omega$ SST models, were first compared in simulations of non-reacting sprays with both single and double injections, followed by the validation and evaluation of two combustion models. The first one is the Representative Interactive Flamelet model (RIF) employing a single flamelet to describe the diffusion flame originating from each injection event. The second one is based on a pre-tabulation technique, called Tabulated Flamelet Progress Variable (TFPV),

Page 14 of 17 which incorporates the local flow and turbulence effects and the transport of a progress variable. Simulations were carried out in different ambient conditions, including the variation of ambient temperature. Lastly, particular emphasis was put on the application of a $k-\omega$ SST model in multiple injection combustion modeling under Diesel-like condition $\left(900 \mathrm{~K}, 15 \% \mathrm{O}_{2}\right.$ by volume and $\left.22.8 \mathrm{~kg} / \mathrm{m}^{3}\right)$. Key findings in this work are summarized below:

- $\quad$ For an inert single injection, both $k-\omega$ SST and $k-\varepsilon$ models showed good agreement with experiments in terms of liquid and vapor penetration, mixture fraction distribution, and radial and axial velocity distributions. These two models differed from each other in predicting axial velocity and mixture fraction along the spray center axis, where higher values around the liquid length were observed in the $k-\omega$ SST case due to the faster liquid penetration.

- For an inert double injection, the spray penetration of the first injection was well captured by $k-\omega$ SST and $k-\varepsilon$ models, while both of them over predicted the second due to the overestimation of the slipstream effect. The $k-\omega$ SST model also predicted a narrower spray distribution but wider zone with richer mixtures due to the higher axial velocity.

- For 800-K and 900-K ambient conditions, the TFPV approach showed a superior performance to the single flamelet formulation RIF model, yielding reasonable agreement with the experimental observations in terms of the second ignition delay, AHRR, flame stabilization and combustion recession. This is due to the incorporation of local flow conditions and transport of progress variable, which makes it possible to properly describe 
the near-nozzle flow field and take into account the effects of radical species from the first injection event. In addition, good prediction of the temporal evolution of total soot mass was seen in both TFPV and RIF models with different tuning parameters for the surface growth step.

- $\quad$ To improve the AHRR prediction at a 750-K ambient, different chemistry mechanisms were tested, revealing the choice of mechanism strongly impacts the computed ignition delays.

- Differences between $k-\omega$ SST and $k-\varepsilon$ models observed in modeling inert injections persisted at the reacting level with impacts on ignition delay and flame structures. Specifically, higher velocities and richer mixture fractions in the near-nozzle region predicted by the $k-\omega$ SST model. This had a strong effect on the computed ignition delays from RIF depending on the average value of stoichiometric scalar dissipation rate. No significant impact was shown in the TFPV case apart from a slightly longer lift-off length. Both turbulence models in conjunction with the TPFV approach reproduced the combustion characteristics with a reasonable accuracy.

- Including the CPU time for table generation, the time consumption of TFPV was almost twice that of RIF, and the use of $k-\omega$ SST model increased the CPU time by a factor of 3 due to the large number of cell counts.

Emerged from these findings, it can be concluded that the TFPV model is a very promising approach for modeling transient spray flames with multiple injections, and that the $k-\omega$ SST model could achieve a comparable accuracy to $k-\varepsilon$ model at the expense of much higher computational costs. In this case, for applying $k-\omega$ SST model in practical Diesel engine simulations and utilizing its benefits in describing the flame-wall contact, reducing the mesh dependency of spray is necessary and will be further investigated in the future.

\section{References}

1. Ismailov, MM. Schock, HJ. "Performance evaluation of a multiburst rapidly operating secondary actuator applied to diesel injection system," SAE Technical Paper 2004-01-0022, 2004, doi: 10.4271/2004-01-0022.

2. Chen, SK. "Simultaneous reduction of NOx and particulate emissions by using multiple injections in a small diesel engine," SAE transactions. SAE Technical Paper 2000-01-3084, 2000:2127-36, doi: 10.4271/2000-01-3084.

3. Tow, T. Pierpont, D. Reitz, RD. "Reducing particulate and NO x emissions by using multiple injections in a heavy duty DI diesel engine," SAE transactions. SAE Technical Paper 940897 , 1994:1403-17, doi: $10.4271 / 940897$.

4. O'Connor, J. Musculus, M. "Post injections for soot reduction in diesel engines: a review of current understanding," SAE International Journal of Engines 2013, 6(1):400-21, doi: 10.4271/2013-01-0917.

5. O'Connor, J. Musculus, M. "In-cylinder mechanisms of soot reduction by close-coupled post-injections as revealed by imaging of soot luminosity and planar laser-induced soot incandescence in a heavy-duty diesel engine," SAE International Journal of Engines 2014, 7(2):673-93, doi: 10.4271/2014-01$\underline{1255}$.

6. O'Connor, J. Musculus, M. "Optical investigation of the reduction of unburned hydrocarbons using close-coupled post injections at LTC conditions in a heavy-duty diesel engine," SAE International Journal of Engines 2013, 6(1):379-99, doi: $\underline{10.4271 / 2013-01-0910 .}$.

Page 15 of 17
7. Anselmi, P. Kashdan, J. Bression, G. Ferrero-Lesur, E, et al., "Improving emissions, noise and fuel economy trade-off by using multiple injection strategies in diesel low temperature combustion (LTC) mode," SAE Technical Paper 2010-01-2162, 2010, doi: 10.4271/2010-01-2162.

8. Husberg, T. Denbratt, I. Karlsson, A. "Analysis of advanced multiple injection strategies in a heavy-duty diesel engine using optical measurements and CFD-simulations," SAE Technical paper 2008-01-1328, 2008, doi: 10.4271/2008-01-1328.

9. Mobasheri, R. Peng, Z. Mirsalim, SM. "Analysis the effect of advanced injection strategies on engine performance and pollutant emissions in a heavy duty DI-diesel engine by CFD modeling," International Journal of Heat and Fluid Flow 2012, 33(1):59-69, doi: 10.1016/j.ijheatfluidflow.2011.10.004.

10. Shrivastava, R. Hessel, R. Reitz, RD. "CFD optimization of DI diesel engine performance and emissions using variable intake valve actuation with boost pressure, EGR and multiple injections," SAE Transactions. SAE Technical Paper 2002-010959, 2002:1612-29, doi: 10.4271/2002-01-0959.

11. Chryssakis, CA. Assanis, DN. Kook, S. Bae, C. "Effect of multiple injections on fuel-air mixing and soot formation in diesel combustion using direct flame visualization and CFD techniques," ASME 2005 Internal Combustion Engine Division Spring Technical Conference. American Society of Mechanical Engineers, 2005:171-80, doi: 10.1115/ICES2005-1016.

12. Hadadpour, A. Jangi, M. Pang, KM. Bai, XS. "The role of a split injection strategy in the mixture formation and combustion of diesel spray: A large-eddy simulation," Proceedings of the Combustion Institute 2019, 37(4):4709-16, doi: 10.1016/j.proci.2018.09.016.

13. Tetrault, P. Plamondon, E. Breuze, M. Hespel, C, et al., "Fuel spray tip penetration model for double injection strategy," SAE Technical Paper 2015-01-0934, 2015, doi: 10.4271/2015-010934.

14. Zhao, W. Wei, H. Jia, M. Lu, Z, et al., "Flame-spray interaction and combustion features in split-injection spray flames under diesel engine-like conditions," Combustion and Flame 2019, 210:204-21, doi: 10.1016/j.combustflame.2019.08.031.

15. Varna, A. Wehrfritz, A. Hawkes, ER. Cleary, MJ, et al., "Application of a multiple mapping conditioning mixing model to ECN Spray A," Proceedings of the Combustion Institute 2019, 37(3):3263-70, doi: 10.1016/j.proci.2018.06.007.

16. Kaario, O. Larmi, M. Tanner, F. "Relating integral length scale to turbulent time scale and comparing $\mathrm{k}-\varepsilon$ and RNG k- $\varepsilon$ turbulence models in diesel combustion simulation," SAE Transactions. SAE Technical Paper 2002-01-1117, 2002:1886900, doi: 10.4271/2002-01-1117.

17. Micklow, GJ. Gong, W. "Combustion modelling for direct injection diesel engines," Proceedings of the Institution of Mechanical Engineers, Part D: Journal of Automobile Engineering 2001, 215(5):651-63, doi: 10.1243/0954407011528248.

18. Wang, B-L. Lee, C-W. Reitz, RD. Miles, PC, et al., "A generalized renormalization group turbulence model and its application to a light-duty diesel engine operating in a lowtemperature combustion regime," International Journal of Engine Research 2013, 14(3):279-92, doi: $10.1177 / 1468087412465379$.

19. Celik, I. Yavuz, I. Smirnov, A. "Large eddy simulations of incylinder turbulence for internal combustion engines: a review," International Journal of Engine Research 2001, 2(2):119-48, doi: $\underline{10.1243 / 1468087011545389 .}$.

20. Menter, FR. "Two-equation eddy-viscosity turbulence models for engineering applications," AIAA journal 1994, 32(8):1598605, doi: $\underline{10.2514 / 3.12149}$. 
21. Menter, F. "Zonal two equation kw turbulence models for aerodynamic flows," 23rd fluid dynamics, plasmadynamics, and lasers conference. 1993:2906, doi: 10.2514/6.1993-2906.

22. Maes, N. Dam, N. Somers, B. Lucchini, T, et al., "Heavy-duty diesel engine spray combustion processes: experiments and numerical simulations," SAE 2018 International Powertrains, Fuels and Lubricants Meeting, FFL 2018. 2018. SAE Technical Paper 2018-01-1689, 2018:1-22, doi: 10.4271/2018-01-1689.

23. Blomberg, CK. Zeugin, L. Pandurangi, SS. Bolla, M, et al., "Modeling Split Injections of ECN "Spray A" Using a Conditional Moment Closure Combustion Model with RANS and LES," SAE International Journal of Engines 2016, 9(4), doi: 10.4271/2016-01-2237.

24. Chishty, M. Bolla, M. Pei, Y. Hawkes, E, et al., "A Numerical Study of 'Spray A'with Multiple-Injections Using the Transported PDF Method," 10th ASPACC Conf. 2015,

25. Bolla, M. Chishty, MA. Hawkes, ER. Kook, S. "Modeling combustion under engine combustion network Spray A conditions with multiple injections using the transported probability density function method," International Journal of Engine Research 2017, 18(1-2):6-14, doi: $\underline{10.1177 / 1468087416689174 .}$.

26. Han, K. Jang, B. Lakew, G. Huh, KY. "Combustion simulation of a diesel engine with Split injections by Lagrangian conditional moment closure model," Combustion Science and Technology 2018, 190(1):1-19, doi: $\underline{10.1080 / 00102202.2017 .1354854 .}$

27. Seo, J. Lee, D. Huh, KY. Chung, J. "Combustion simulation of a diesel engine in the pHCCI mode with split injections by the spatially integrated CMC model," Combustion Science and Technology 2010, 182(9):1241-60, doi: 10.1080/00102201003639300.

28. Doran, EM. Pitsch, H. Cook, DJ. "Multi-dimensional flamelet modeling of multiple injection diesel engines," SAE Technical Paper 2012-01-0133, 2012, doi: 10.4271/2012-01-0133.

29. Hasse, C. Peters, N. "A two mixture fraction flamelet model applied to split injections in a DI Diesel engine," Proceedings of the Combustion Institute 2005, 30(2):2755-62, doi: 10.1016/i.proci.2004.08.166.

30. Hasse, CW. "A two-dimensional flamelet model for multiple injections in diesel engines, " Cuvillier Verlag, 2004.

31. Ehleskog, R. Ochoterena, RL. "Soot evolution in multiple injection diesel flames," SAE Technical Paper 2008-01-2470, 2008, doi: 10.4271/2008-01-2470.

32. Moiz, AA. Ameen, MM. Lee, S-Y. Som, S. "Study of soot production for double injections of $n$-dodecane in CI engine-like conditions," Combustion and Flame 2016, 173:123-31, doi: 10.1016/j.combustflame.2016.08.005.

33. Skeen, SA. Manin, J. Pickett, LM. Cenker, E, et al., "A progress review on soot experiments and modeling in the engine combustion network (ECN)," SAE International Journal of Engines 2016, 9(2):883-98, doi: 10.4271/2016-01-0734.

34. D'Errico, G. Lucchini, T. Hardy, G. Tap, F, et al., "Combustion Modeling in Heavy Duty Diesel Engines Using Detailed Chemistry and Turbulence-Chemistry Interaction," 1. SAE Technical Paper 2015-01-0375, 2015, doi: 10.4271/2015-01$\underline{0375}$.

35. Lucchini, T. D'Errico, G. Onorati, A. Frassoldati, A, et al., "Modeling non-premixed combustion using tabulated Kinetics and different fame structure assumptions," 10. SAE Technical Paper 2017-01-0556, 2017:593-607, doi: 10.4271/2017-01$\underline{0556 .}$.

36. Michel, J-B. Colin, O. "A tabulated diffusion flame model applied to diesel engine simulations," International Journal of
Engine Research 2014, 15(3):346-69, doi: $10.1177 / 1468087413488590$.

37. Lehtiniemi, H. Zhang, Y. Rawat, R. Mauss, F. "Efficient 3-D CFD combustion modeling with transient flamelet models," SAE technical paper 2008-01-0957, 2008, doi: 10.4271/200801-0957.

38. Naud, B. Novella, R. Pastor, JM. Winklinger, JF. "RANS modelling of a lifted $\mathrm{H} 2 / \mathrm{N} 2$ flame using an unsteady flamelet progress variable approach with presumed PDF," Combustion and Flame 2015, 162(4):893-906, doi: 10.1016/j.combustflame.2014.09.014.

39. Michel, J-B. Colin, O. Angelberger, C. Veynante, D. "Using the tabulated diffusion flamelet model ADF-PCM to simulate a lifted methane-air jet flame," Combustion and Flame 2009, 156(7):1318-31, doi: 10.1016/j.combustflame.2008.12.012.

40. Lucchini, T. D'Errico, G. Cerri, T. Onorati, A, et al., "Experimental validation of combustion models for diesel engines based on tabulated kinetics in a wide range of operating conditions," 2017. SAE Technical Paper 2017-24-0029, 2017:115, doi: 10.4271/2017-24-0029.

41. Zhou, Q. Lucchini, T. D'Errico, G. Hardy, G. "Validation of Diesel Combustion Models with Turbulence Chemistry Interaction and Detailed Kinetics," SAE Technical Paper, 2019, SAE Technical Paper 2019-24-0088.

42. Weller, HG. Tabor, G. Jasak, H. Fureby, C. "A tensorial approach to computational continuum mechanics using objectoriented techniques," Computers in physics 1998, 12(6):620-31, doi: $10.1063 / 1.168744$

43. Lucchini, T. Della Torre, A. D'Errico, G. Montenegro, G, et al., "Automatic mesh generation for CFD simulations of directinjection engines," SAE Technical Paper 2015-01-0376, 2015, doi: $10.4271 / 2015-01-0376$.

44. Lucchini, T. D’Errico, G. Onorati, A. Bonandrini, G, et al., "Development and application of a computational fluid dynamics methodology to predict fuel-air mixing and sources of soot formation in gasoline direct injection engines," International Journal of Engine Research 2014, 15(5):581-96, doi: $10.1177 / 1468087413500297$.

45. Lucchini, T. Fiocco, M. Torelli, R. D'Errico, G. "Automatic mech generation for full-cycle CFD modeling of IC engines: application to the TCC test case," SAE Technical Paper 201401-1131, 2014, doi: 10.4271/2014-01-1131.

46. Skeen, S. Manin, J. Pickett, LM. "Visualization of ignition processes in high-pressure sprays with multiple injections of ndodecane," SAE International Journal of Engines 2015, 8(2):696-715, doi: 10.4271/2015-01-0799.

47. Maes, N. Bakker, P. Dam, N. Somers, B. "Transient flame development in a constant-volume vessel using a split-scheme injection strategy," SAE International Journal of Fuels and Lubricants 2017, 10(2):318-27, doi: 10.4271/2017-01-0815.

48. Skeen, SA. Manin, J. Pickett, LM. "Simultaneous formaldehyde PLIF and high-speed schlieren imaging for ignition visualization in high-pressure spray flames," Proceedings of the Combustion Institute 2015, 35(3):3167-74, doi: 10.1016/j.proci.2014.06.040.

49. Peters, N. "Laminar flamelet concepts in turbulent combustion," Symposium (International) on Combustion. 21. Elsevier, 1988:1231-50, doi: 10.1016/S0082-0784(88)80355-2.

50. Peters, N. "Laminar diffusion flamelet models in non-premixed turbulent combustion," Progress in energy and combustion science 1984, 10(3):319-39, doi: 10.1016/0360-1285(84)90114$\underline{X}$.

51. D'Errico, G. "Comparison of well-mixed and multiple representative interactive flamelet approaches for diesel spray combustion modelling," Combustion Theory \& Modelling 2014, 18(1):65-88, doi: 10.1080/13647830.2013.860238.

Page 16 of 17 
52. D'Errico, G. Lucchini, T. Hardy, G. Tap, F, et al., "Combustion Modeling in Heavy Duty Diesel Engines Using Detailed Chemistry and Turbulence-Chemistry Interaction," SAE Technical Paper 2015-01-0375, 2015, doi: 10.4271/2015-010375 .

53. Singh, S. Reitz, RD. Musculus, MP. "Comparison of the characteristic time (CTC), representative interactive flamelet (RIF), and direct integration with detailed chemistry combustion models against optical diagnostic data for multi-mode combustion in a heavy-duty DI diesel engine," SAE Technical Paper 2006-01-0055, 2006, doi: 10.4271/2006-01-0055.

54. Lucchini, T. D'Errico, G. Onorati, A. Frassoldati, A, et al., "Modeling non-premixed combustion using tabulated Kinetics and different fame structure assumptions," SAE International Journal of Engines 2017-01-0556, 2017, 10(2):593-607, doi: 10.4271/2017-01-0556.

55. Lucchini, T. D'Errico, G. Cerri, T. Onorati, A, et al., "Experimental validation of combustion models for diesel engines based on tabulated kinetics in a wide range of operating conditions," SAE Technical Paper 2017-24-0029, 2017, doi: 10.4271/2017-24-0029.

56. Leung, KM. Lindstedt, RP. Jones, W. "A simplified reaction mechanism for soot formation in nonpremixed flames," Combustion and flame 1991, 87(3-4):289-305, doi: 10.1016/0010-2180(91)90114-Q.

57. Pope, S. "An explanation of the turbulent round-jet/plane-jet anomaly," AIAA journal 1978, 16(3):279-81, doi: 10.2514/3.7521.

58. Ferziger, JH. Peric, M. "Computational methods for fluid dynamics," Springer Science \& Business Media, 2012.

59. Reitz, RD. "Modeling atomization processes in high-pressure vaporizing sprays," Atomisation and Spray Technology 1987, 3(4):309-37,

60. Reitz, RD. Diwakar, R. "Effect of drop breakup on fuel sprays,"

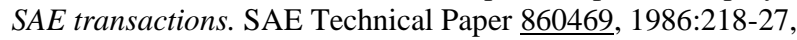
doi: $\underline{10.4271 / 860469}$.

61. Baumgarten, C. "Mixture formation in internal combustion engines, " Springer Science \& Business Media, 2006.

62. Lucchini, T. D’Errico, G. Ettorre, D. "Numerical investigation of the spray-mesh-turbulence interactions for high-pressure, evaporating sprays at engine conditions," International Journal of Heat and Fluid Flow 2011, 32(1):285-97, doi: 10.1016/i.ijheatfluidflow.2010.07.006.

63. "Engine Combustion Network," http://www.sandia.gov/ecn/cvdata/dsearch/frameset.php.

64. Pickett, LM. Manin, J. Genzale, CL. Siebers, DL, et al., "Relationship Between Diesel Fuel Spray Vapor Penetration/Dispersion and Local Fuel Mixture Fraction," SAE Int J Engines 2011, 4(1):764-99, doi: 10.4271/2011-01-0686.

65. Ranzi, E. Frassoldati, A. Stagni, A. Pelucchi, M, et al., "Reduced kinetic schemes of complex reaction systems: fossil and biomass-derived transportation fuels," International Journal of Chemical Kinetics 2014, 46(9):512-42, doi: 10.1002/kin.20867.

66. Stagni, A. Cuoci, A. Frassoldati, A. Faravelli, T, et al., "Lumping and reduction of detailed kinetic schemes: an effective coupling," Industrial \& Engineering Chemistry Research 2013, 53(22):9004-16, doi: 10.1021/ie403272f.

67. Yao, T. Pei, Y. Zhong, B-J. Som, S, et al., "A compact skeletal mechanism for n-dodecane with optimized semi-global lowtemperature chemistry for diesel engine simulations," Fuel 2017, 191:339-49, doi: 10.1016/j.fuel.2016.11.083.

68. Payri, F. García-Oliver, JM. Novella, R. Pérez-Sánchez, EJ. "Influence of the n-dodecane chemical mechanism on the CFD modelling of the diesel-like ECN Spray A flame structure at

Page 17 of 17

different ambient conditions," Combustion and Flame 2019, 208:198-218, doi: 10.1016/i.combustflame.2019.06.032.

\section{Contact Information}

Qiyan Zhou

Department of Energy, Politecnico di Milano

Via Lambruschini, 4

20156 Milano, Italy

qiyan.zhou@polimi.it

\section{Acknowledgments}

Authors acknowledge the financial support from FPT-

Motorenforschuang AG.Michael Harter (FPT). The first author also gratefully acknowledges the financial support from the China

Scholarship Council (No. 201806230180) and Natural Science Foundation of China (No. 51425602, 51961135105) for her study in Politecnico di Milano, Italy.

\section{Definitions/Abbreviations}

RIF

TFPV

UHC

LTC

PM

TRIF

TWM

CFD

EGR

PISO

SIMPLE

AHRR

ASOI

ID
Representative Interactive Flamelet

Tabulated Flamelet Progress Variable

Unburned Hydrocarbon

Low Temperature

Combustion

Particulate Matter

Tabulated Representative Interactive Flamelet

Tabulated Well-Mixed

Computational Fluid Dynamics

Exhaust gas recirculation

Pressure-Implicit with Splitting of Operators

Simple Implicit Method for Pressure Linked Equations

Apparent Heat Release Rate

After Start of Injection

Ignition Delay 